Article

\title{
Proportioning and Characterization of Reactive Powder Concrete for an Energy Storage Pile Application
}

\author{
Umut Bektimirova, Chang-Seon Shon *(D), Dichuan Zhang *(D), Eldar Sharafutdinov and \\ Jong R. Kim
}

Department of Civil and Environmental Engineering, Nazarbayev University, Astana 010000, Kazakhstan; ubakhbergenova@nu.edu.kz (U.B.); esharafutdinov@nu.edu.kz (E.S.); jong.kim@nu.edu.kz (J.R.K.)

* Correspondence: chang.shon@nu.edu.kz (C.-S.S.); dichuan.zhang@nu.edu.kz (D.Z.); Tel.: +7-(7172)-70-64-22 (C.-S.S.); +7-(7172)-70-91-45 (D.Z.)

Received: 12 October 2018; Accepted: 15 November 2018; Published: 6 December 2018

\begin{abstract}
Reactive Powder Concrete (RPC) is a newly emerging concrete material that is being used for various applications where high-strength concrete is required. RPC is obtained by removing coarse aggregates and adding fine powders such as silica fume into the concrete mixture. This research has focused on the proportioning and characterization of RPC mixture to be used as a material for energy storage pile application. For mixture parameters, the water-to-binder ratio (WB), silica fume (SF) content, and normal and warm temperature curing have been selected. The relative flowability, penetration resistance, setting time, drying shrinkage, and compressive and flexural strengths were evaluated. Based on the test results, the mixture with $\mathrm{WB}=0.22$ and $\mathrm{SF}=20 \%$ was the best mixture with the highest tensile strength and other characteristics. Response surface methodology (RSM) was used to design the experiments and find the optimum mixture proportions to achieve the highest compressive strength. The optimum WB and SF content to achieve the highest strength for combined ages ( 7 days, 28 days, and 56 days) was determined to be $\mathrm{WB}=0.213$ and $\mathrm{SF}=20 \%$. Through the comparison between the test results and the required strength from analytical simulations, the RPC studied in this paper was deemed to be suitable for the energy storage pile.
\end{abstract}

Keywords: reactive powder concrete (RPC); energy storage pile; silica fume; water-to-binder ratio; response surface methodology (RSM); compressive strength; flexural strength; drying shrinkage

\section{Introduction}

Reactive powder concrete (RPC) is a newly emerging material that is typically composed of cement, silica fume, and sand, along with the use of fibers and superplasticizer. It is characterized by high compressive and tensile strength, low porosity, and high ductility [1]. These properties of RPC are obtained by (i) the suppression of a weak interfacial transition zone (ITZ) that is normally developed around the aggregate through eliminating the coarse aggregate; (ii) the refinement of the hydrated paste microstructure using silica fume (SF) and elevated temperature curing; (iii) the use of superplasticizer (SP) to decrease the water-to-cementitious material ratio; and (iv) the addition of steel and synthetic microfibers [2-4].

Unlike ordinary concrete, the replacement of coarse aggregate with fine sand renders a better uniformity of RPC and an enhanced ITZ in RPC. Ahmad et al. [5] and Tam et al. [6] reported that finely and well-graded quartz sand is typically used instead of using coarse aggregate. The particle size of sand is ranged from $150 \mu \mathrm{m}$ to $600 \mu \mathrm{m}$, with a mean value of $250 \mu \mathrm{m}$. The sand particle size smaller than $150 \mu \mathrm{m}$ is not used, because it causes interference with the largest cement particles. Ji et al. [7] 
studied the effects of sand particle size and gradation on the strength of reactive powder concrete. They found that a higher strength of RPC was related to a smaller maximum size and larger packing degree of the sand, because of the enhanced ITZ between the sand and the hardened cement paste.

Silica fume (SF) is also incorporated into RPC mixture as a partial replacement of cement. Similar to other supplementary cementitious materials, SF provides a pore refinement effect either by a filler effect or pozzolanic reaction with the calcium hydroxide $(\mathrm{CH})$ produced from the primary hydration of cement. This leads to the improved microstructure of RPC and a higher strength than ordinary concrete $[2,8,9]$. However, an optimum SF content in RPC typically ranged from $10 \%$ to $25 \%$ by the replacement of cement by mass, resulting in good workability and strength properties $[10,11]$. Ahmad et al. [5] observed that increasing the SF content has a positive effect on the compressive strength and modulus of rupture of RPC only to a certain optimum point, while a further increase of SF content does not result in a significant strength rise in RPC.

Another important factor that affects the property of RPC is the curing condition. Generally, RPC is cured in the form of either autoclave curing through applying heat and pressure simultaneously on fresh RPC samples, or high temperature thermal/heat curing using steam curing, hot water bath curing, and hot air curing. Depending on the preset pressure and temperature, a compressive strength of up to $500 \mathrm{MPa}$ was achieved when cured at the autoclave [12-15]. Under high-temperature thermal curing, silica fume dissolves rapidly, and the rate of reaction between SF and $\mathrm{CH}$ led to a high early strength gain of RPC increases [16,17]. Hiremath and Yaragal [18] investigated the effect of different curing regimes (ambient air curing, hot air curing, hot water bath curing, and accelerated curing) and durations on the early strength development of reactive powder concrete. They found that the strength development of RPC is strongly dependent on the temperature and duration of exposure. They also observed that among four different curing methods, hot water bath curing gives higher strength, but the combined curing regime (e.g., hot water curing and hot air curing) shows better compressive strength development than a single curing regime.

Changing the water-to-binder ratio (WB) is another important parameter that affects the strength of RPC. Decreasing the WB positively affects both the compressive strength and modulus of rupture of RPC [5]. However, when the WB is decreased beyond a certain limit, the workability of obtained concrete was not sufficient for comfortable handling and placing [8]. Moreover, since the addition of SF leads to a high water demand for RPC mixtures, it is necessary to add SP to maintain the slump level of RPC. Ahmad [5] suggested that the optimum WB range for RPC is from 0.15 to 0.24 in order to achieve its required flowability along with the use of SP.

On the other hand, many researchers have studied the characterization of RPC mixtures with the addition of steel or other fibers. Since RPC is a strong and brittle material, fibers are typically added to the RPC mixture to improve its tensile strength and ductility. Steel fibers in RPC change the failure behavior of the material from sudden explosive to ductile, which makes it more suitable for many applications $[19,20]$. Typical steel fiber content and a steel fiber to total binder ratio are $190-250 \mathrm{~kg} / \mathrm{m}^{3}$ and $0.15-0.30$ (by weight), respectively $[5,11,14]$.

Although many researchers around the world have investigated the properties of RPC, including mixture proportion, mechanical characteristics, and durability, a wide implementation of RPC as a construction material into construction business is limited because of its relatively high cost of production [21,22]. The addition of expensive steel fibers and the special treatment of a curing regimen influence the overall cost of RPC [8]. Moreover, since RPC is a newly emerging material, there is no standard procedure for mixture proportioning and the determination of material properties. As a part of research studies using RPC as a material for an energy storage pile foundation system [23-25], this study focuses on the determination of properties of RPC without the addition of steel fibers in normal temperature and warm temperature curing regimes. For the energy storage pile foundation system, the hollow sectioned pile is required to store the excess energy produced in off-peak hours in the form of compressed air. A reduced cross-sectional area and additional tensile stresses coming from the pressurized air inside the pile require the pile to withstand complicated loading conditions. 
Therefore, RPC has the potential to be a suitable material because of its considerable high compressive, tensile strengths, and low porosity for bearing, crack prevention, and air tightness.

This study has focused on a mixture proportion of RPC without the addition of steel fibers to achieve an appropriate compressive strength under normal and warm temperature curing conditions. Fresh properties such as the flowability and setting time have also been investigated in this study. Moreover, the drying shrinkage of RPC due to its high cement and SF contents has been checked. To optimize the mixture proportion of RPC, the response surface method (RSM) has been selected. To check whether RPC is applicable for the energy storage pile foundation, extensive finite element simulations were conducted to determine critical stress demands in the pile foundation as discussed in Zhang et al. [26]. This paper compares the strength of the RPC achieved in this study to the maximum stress demand obtained from analytical simulation.

\section{Materials and Experimental Procedures}

\subsection{Materials}

ASTM Type I ordinary Portland cement and densified SF, which are available locally, were used as binder materials for RPC in this study. The specific gravity of cement is 3.15, and SF has a specific gravity of 2.22. Their chemical compositions (by mass) are shown in Table 1.

Table 1. Chemical composition of cement and silica fume (SF).

\begin{tabular}{ccc}
\hline Components & Cement (by Mass) & SF (by Mass) \\
\hline $\mathrm{CaO}[\%]$ & 63.81 & 0.47 \\
$\mathrm{SiO}_{2}[\%]$ & 21.45 & 95.6 \\
$\mathrm{Al}_{2} \mathrm{O}_{3}[\%]$ & 4.45 & 0.45 \\
$\mathrm{Fe}_{2} \mathrm{O}_{3}[\%]$ & 3.07 & 0.05 \\
$\mathrm{SO}_{3}[\%]$ & 2.46 & - \\
$\mathrm{MgO}[\%]$ & 2.42 & - \\
$\mathrm{K}_{2} \mathrm{O}[\%]$ & 0.83 & - \\
Others & 1.02 & 1.53 \\
Loss on Ignition [\%] & 0.49 & 1.90 \\
\hline
\end{tabular}

Fine quartz sand with a bulk specific gravity of 2.4 , absorption capacity of $6.2 \%$, fineness modules of 1.02 was used as aggregate for RPC mixtures. A liquid superplasticizer (SP) (Master Glenium ACE 430 , specific gravity of 1.06) and ordinary tap water with a specific gravity of 1.0 were also used in the mixtures.

\subsection{Design of Mixture Proportions Using Response Surface Method}

The response surface method (RSM) is a special statistic method of a single-variable and orthogonal design. RSM evaluates the effect of variables on the target in three-dimensional (3D) space. The impact of the various dosage of SF (mass replacement of cement) and different WB on the compressive strength of RPC was analyzed by RSM. Central composite design (CCD) factors were used in this study. Equation (1) represents the quadratic model of the target with respect to variables:

$$
y=\beta_{j, 0}+\sum_{i=1}^{k} \beta_{i} x_{i}+\sum_{i=1}^{k} \beta_{i i} x_{i}^{2}+\sum_{i} \sum_{j} \beta_{i j} x_{i} x_{j}+\varepsilon
$$

where $y$-predicted response (compressive strength), $x_{i}$ and $x_{j}$-coded values of the variables (SF content and WB), $i$-linear coefficient, $j$-quadratic coefficient, $\beta$-regression coefficient, $k$-the number of factors in the study, and $\varepsilon$-random error.

The variation of SF content and WB in the mixture proportion was designed using Minitab statistic software; corresponding CCD values were designed for them as presented in Table 2. In addition to 
the nine mixtures required for the RSM, three plain concrete mixtures with different WB were included in the study to act as a baseline for the characterization of RPC.

Six key mixtures (marked in bold in Table 2) were chosen for the further investigation of RPC such as modulus of rupture, drying shrinkage, and the effect of warm curing on the properties of RPC. The six key mixtures include the effect of SF and WB on properties of RPC when WB and SF content are constant, respectively. In addition, one of the plain mixtures was chosen to provide a baseline property.

The quantity of mixture components was determined using the absolute volume method, which simply implies that the amount of material required to produce $1 \mathrm{~m}^{3}$ of the mixture was calculated based on the specific gravities of each material. The optimum dosage of SP was determined to provide a sufficient workability for the mixture (the target value of flowability was $180 \pm 30 \mathrm{~mm}$ ). The SP content is varied from mixture to mixture. However, in four out of six key mixtures, SP dosage was kept constant ( $\mathrm{SP}=1.5 \%$ of total binder content) to eliminate the effect of $\mathrm{SP}$ on the properties of RPC. In the remaining two mixtures, SP dosage was optimized as close to $1.5 \%$ as possible in order to obtain the adequate followability of the mixture. The final mixture proportioning of 12 mixtures is provided in Table 2.

Table 2. Mixture proportion of Reactive Powder Concrete (RPC) $\left(\mathrm{kg} / \mathrm{m}^{3}\right)$ and response surface method (RSM) values.

\begin{tabular}{|c|c|c|c|c|c|c|c|c|c|c|c|}
\hline No. & Mixture ID & WB & $\begin{array}{l}\text { Coded } \\
\text { values } \\
\text { of WB }\end{array}$ & $\begin{array}{l}\mathrm{SF} \\
{[\%]}\end{array}$ & $\begin{array}{l}\text { Coded } \\
\text { values } \\
\text { of SF }\end{array}$ & $\begin{array}{l}\text { Cement } \\
\mathrm{kg} / \mathrm{m}^{3} \\
\left(\mathrm{~m}^{3}\right)\end{array}$ & $\begin{array}{c}\mathrm{SF} \\
\mathrm{kg} / \mathrm{m}^{3} \\
\left(\mathrm{~m}^{3}\right)\end{array}$ & $\begin{array}{c}\text { Sand } \\
\mathrm{kg} / \mathrm{m}^{3} \\
\left(\mathrm{~m}^{3}\right)\end{array}$ & $\begin{array}{c}\text { Water } \\
\mathrm{kg} / \mathrm{m}^{3} \\
\left(\mathrm{~m}^{3}\right)\end{array}$ & $\begin{array}{c}\text { Total } \\
\text { Vol. } \mathrm{m}^{3}\end{array}$ & $\begin{array}{l}\text { SP } \\
{[\%]}\end{array}$ \\
\hline 1 & $0.18 W B-20 S F$ & 0.18 & -1.41 & 20 & 0 & $\begin{array}{c}1000 \\
(0.317)\end{array}$ & $\begin{array}{c}200 \\
(0.090)\end{array}$ & $\begin{array}{c}903 \\
(0.376)\end{array}$ & $\begin{array}{c}216 \\
(0.216)\end{array}$ & 1.00 & 2 \\
\hline 2 & 0.1917WB-23.54SF & 0.1917 & -1 & 23.54 & 1 & $\begin{array}{c}971 \\
(0.308)\end{array}$ & $\begin{array}{c}229 \\
(0.103)\end{array}$ & $\begin{array}{c}861 \\
(0.359)\end{array}$ & $\begin{array}{c}230 \\
(0.230)\end{array}$ & 1.00 & 2.5 \\
\hline 3 & $0.22 \mathrm{WB}-25 \mathrm{SF}$ & 0.22 & 0 & 25 & 1.41 & $\begin{array}{c}960 \\
(0.305)\end{array}$ & $\begin{array}{c}240 \\
(0.108)\end{array}$ & $\begin{array}{c}776 \\
(0.323)\end{array}$ & $\begin{array}{c}264 \\
(0.264)\end{array}$ & 1.00 & 1.5 \\
\hline 4 & $0.22 \mathrm{WB}-20 \mathrm{SF}$ & 0.22 & 0 & 20 & 0 & $\begin{array}{c}1000 \\
(0.317)\end{array}$ & $\begin{array}{c}200 \\
(0.090)\end{array}$ & $\begin{array}{c}788 \\
(0.328)\end{array}$ & $\begin{array}{c}264 \\
(0.264)\end{array}$ & 1.00 & 1.5 \\
\hline 5 & $0.2483 \mathrm{WB}-23.54 \mathrm{SF}$ & 0.2483 & 1 & 23.54 & 1 & $\begin{array}{c}971 \\
(0.308)\end{array}$ & $\begin{array}{c}229 \\
(0.103)\end{array}$ & $\begin{array}{c}698 \\
(0.291)\end{array}$ & $\begin{array}{c}298 \\
(0.298)\end{array}$ & 1.00 & 1.125 \\
\hline 6 & $0.26 \mathrm{WB}-20 \mathrm{SF}$ & 0.26 & 1.41 & 20 & 0 & $\begin{array}{c}1000 \\
(0.317)\end{array}$ & $\begin{array}{c}200 \\
(0.090)\end{array}$ & $\begin{array}{c}673 \\
(0.280)\end{array}$ & $\begin{array}{c}312 \\
(0.312)\end{array}$ & 1.00 & 1.5 \\
\hline 7 & $0.2483 \mathrm{WB}-16.46 \mathrm{SF}$ & 0.2483 & 1 & 16.46 & -1 & $\begin{array}{c}1030 \\
(0.327)\end{array}$ & $\begin{array}{c}170 \\
(0.077)\end{array}$ & $\begin{array}{c}716 \\
(0.298)\end{array}$ & $\begin{array}{c}298 \\
(0.298)\end{array}$ & 1.00 & 1 \\
\hline 8 & $0.22 \mathrm{WB}-15 \mathrm{SF}$ & 0.22 & 0 & 15 & -1.41 & $\begin{array}{c}1043 \\
(0.331)\end{array}$ & $\begin{array}{c}157 \\
(0.071)\end{array}$ & $\begin{array}{c}802 \\
(0.334)\end{array}$ & $\begin{array}{c}264 \\
(0.264)\end{array}$ & 1.00 & 1.5 \\
\hline 9 & 0.1917WB-16.46SF & 0.1917 & -1 & 16.46 & -1 & $\begin{array}{c}1030 \\
(0.327)\end{array}$ & $\begin{array}{c}170 \\
(0.077)\end{array}$ & $\begin{array}{c}879 \\
(0.366)\end{array}$ & $\begin{array}{c}230 \\
(0.230)\end{array}$ & 1.00 & 2.50 \\
\hline 10 & 0.18WB-0SF & 0.18 & NA & 0 & NA & $\begin{array}{c}1200 \\
(0.381)\end{array}$ & $\begin{array}{c}0 \\
(0)\end{array}$ & $\begin{array}{c}967 \\
(0.403)\end{array}$ & $\begin{array}{c}216 \\
(0.216)\end{array}$ & 1.00 & 1.5 \\
\hline 11 & $0.22 \mathrm{WB}-0 \mathrm{SF}$ & 0.22 & NA & 0 & NA & $\begin{array}{c}1200 \\
(0.381)\end{array}$ & $\begin{array}{c}0 \\
(0)\end{array}$ & $\begin{array}{c}852 \\
(0.355)\end{array}$ & $\begin{array}{c}264 \\
(0.264)\end{array}$ & 1.00 & 1.0 \\
\hline 12 & $0.26 \mathrm{WB}-0 \mathrm{SF}$ & 0.26 & NA & 0 & NA & $\begin{array}{c}1200 \\
(0.381)\end{array}$ & $\begin{array}{c}0 \\
(0)\end{array}$ & $\begin{array}{c}737 \\
(0.307)\end{array}$ & $\begin{array}{c}312 \\
(0.312)\end{array}$ & 1.00 & 0.5 \\
\hline
\end{tabular}

\subsection{Mixing Procedure and Preparation of Testing Specimens}

For the mixing procedure, cement and SF were added to the pan-type mixer of 100-L capacity and dry-mixed for $30 \mathrm{~s}$. First, 50\% of water was added and mixed for $90 \mathrm{~s}$. Then, the aggregate was added and mixed for $60 \mathrm{~s}$. SP dissolved in the remaining $50 \%$ of the water was added to the mixture and continuously wet-mixed for $180 \mathrm{~s}$. After a 60-s stop period to mix the particles adhered to the walls of the mixer by hand, the concrete mixture was mixed for an additional $120 \mathrm{~s}$. The total mixing time was about nine min.

As soon as mixing was completed, the RPC for compressive strength was cast in a $50 \mathrm{~mm} \times$ $50 \mathrm{~mm} \times 50 \mathrm{~mm}$ cube mold, as required in ASTM C109 [27]. The casting of specimens was completed in two layers. Each layer was taped with a rubber stick and shaken to achieve better compaction. The increased surface of the concrete was removed by a scraper. After casting was done, molds were covered with plastic sheets to prevent moisture evaporation. After $24 \mathrm{~h}$, RPC specimens were demolded and cured in water baths at required conditions (saturated lime solution under $23 \pm 2{ }^{\circ} \mathrm{C}$ or 
$40 \pm 2{ }^{\circ} \mathrm{C}$ ) till the age of 3 days, 7 days, 28 days, and 56 days. Additionally, the $40 \mathrm{~mm} \times 40 \mathrm{~mm} \times$ $160 \mathrm{~mm}$ prismatic specimen was prepared for flexural strength, while the $25 \mathrm{~mm} \times 25 \mathrm{~mm} \times 285 \mathrm{~mm}$ prism having a 250-mm gauge length was cast for a dying shrinkage test. At the corresponding age, hardened concrete tests were performed.

\subsection{Fresh and Hardened Concrete Tests}

Immediately after mixing was complete, a standard flow test to check the workability was conducted, as specified in ASTM C1437 [28]. The mini-flow cone was filled with fresh concrete. The initial concrete diameter was recorded as the average from four measurements; afterwards, the mini-cone was slowly removed to allow the concrete to flow. The flow table was then dropped 25 times within $15 \mathrm{~s}$. The final diameter of the concrete was recorded as the average of four readings. Equation (2) was used to calculate the relative flow area for each mixture:

$$
\Gamma_{\mathrm{m}}=\frac{\left(d_{1} \times d_{2}\right)-d_{0}^{2}}{d_{0}^{2}}
$$

where, $\Gamma_{\mathrm{m}}=$ relative flow area; $d_{1}$ and $d_{2}=$ measured flow diameter after dropping; $d_{0}=$ flow cone diameter $(100 \mathrm{~mm})$, and $d_{0 \text {-avg }}=$ average value of $d_{0}^{1}$ and $d_{0}^{2}$ (measured flow diameter before dropping).

The setting time of RPC was determined for six key mixtures according to ASTM C403 [29]. The initial and final set times were calculated from the plot of penetration resistance versus time elapsed from the initial contact of water and binder using simple linear regression from Equation (3):

$$
\log (P R)=a+b \log (t)
$$

where, $P R=$ penetration resistance; $t=$ the time elapsed from the initial contact of the water and binder; and $a$ and $b=$ regression constants. The initial set time corresponds to $3.45 \mathrm{MPa}$, and the final setting time corresponds to $27.6 \mathrm{MPa}$.

As shown in Figure 1, a compressive strength test and flexural strength test called the modulus of rupture (MOR) were performed according to guidelines of ASTM C 109 [27] and ASTM C 293 [30], irrespectively. The average of three specimens at the testing age was used for analysis. The MOR was calculated using Equation (4):

$$
M o R=\frac{3 P L}{2 b d^{2}}
$$

where $P=$ maximum applied load; $L=$ span length; $b=$ average width of the specimen; and $d=$ average depth of the specimen.
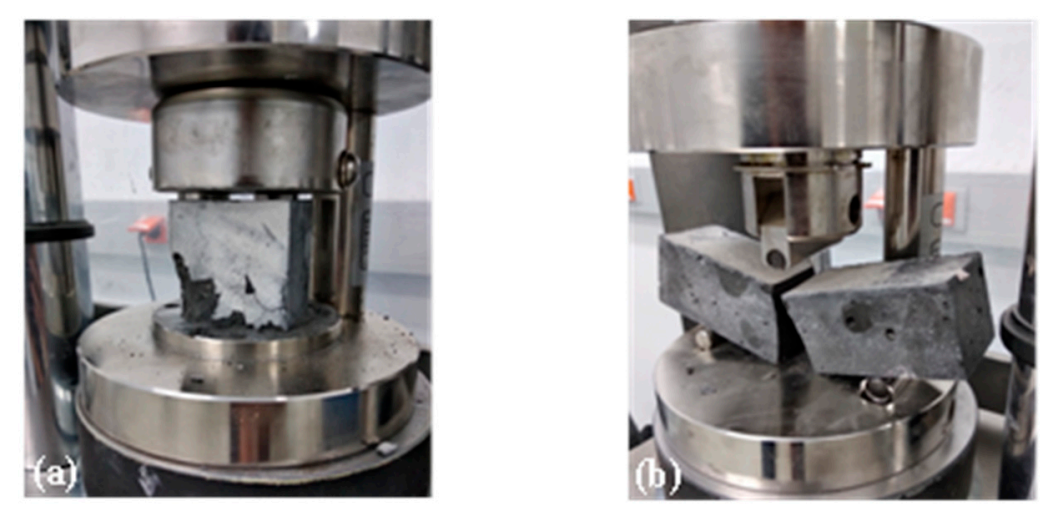

Figure 1. Strength test setup: (a) compressive strength test; (b) flexural strength test.

The drying shrinkage (time-dependent volume change) test of RPC was performed in accordance with ASTM C 157 and ASTM C490 [31,32]. A digital length comparator with an accuracy of \pm 0.0001 $\mathrm{mm}$ was also used to measure the linear dimension variation of specimens along the longitudinal 
axis. The specimens were stored in an environmental chamber where the temperature was $23 \pm 2{ }^{\circ} \mathrm{C}$, and relative humidity was $50 \pm 4 \% \mathrm{RH}$. The measurements for autogenous shrinkage (one-day cured specimen) were taken at the following intervals: every day up to an age of 7 days, every 3 days up to an age of 28 days, and every 14 days for up to an age of 56 days. The measurements for a seven-day cured specimen were taken at the following intervals: every 3 days for an age of up to 28 days, and every 14 days for an age of up to 56 days. Then, the drying shrinkage value was calculated using Equation (5):

$$
L=\frac{\left(L_{x}-L_{i}\right)}{G} \times 100
$$

where, $L=$ change in the length at $x$ age $(\%) ; L_{x}(\mathrm{~mm})=($ comparator reading of specimen at $x$ age $)-$ (comparator reading of reference bar at $x$ age); $L_{i}(\mathrm{~mm})=$ (initial comparator reading of specimen) (comparator reading of reference bar at the same time); and $G=$ nominal gauge length $(250 \mathrm{~mm})$.

\section{Test Results}

\subsection{Fresh Properties of RPC}

\subsubsection{Flowability of RPC}

Flowability is one of the important properties of RPC, because the mixture of RPC contains a relatively high amount $\mathrm{SF}$, which makes the concrete sticky in nature and hard to handle. The results of the flow table test are given in Table 3. Except for the mixture 0.18WB-0SF, the final flow values of RPC after dropping the flow table ranged from $150 \mathrm{~mm}$ to $250 \mathrm{~mm}$ for all of the mixtures, which ensured comfortable concrete placing at the sufficient level of workability. It should be noted that the mixture of $0.26 \mathrm{WB}-20 \mathrm{SF}$ has the highest WB and $1.5 \%$ SP content.

Table 3. Flowability and porosity test results.

\begin{tabular}{|c|c|c|c|c|c|c|c|c|c|}
\hline \multirow{2}{*}{ No. } & \multirow{2}{*}{ Mixture ID } & \multicolumn{2}{|c|}{ Before Dropping } & \multicolumn{2}{|c|}{ After Dropping } & \multirow{2}{*}{$\Gamma_{\mathrm{m}}$} & \multicolumn{3}{|c|}{ Porosity } \\
\hline & & $d_{0}^{1}(\mathrm{~mm})$ & $d_{0}^{2}(\mathrm{~mm})$ & $d_{1}(\mathrm{~mm})$ & $d_{2}(\mathrm{~mm})$ & & $7-d$ & 28-d & 56-d \\
\hline 1 & 0.18WB-20SF & 110 & 110 & 150 & 150 & 1.25 & 3.84 & 4.14 & 5.28 \\
\hline 2 & 0.1917WB-23.54SF & 100 & 107 & 195 & 200 & 2.90 & 5.27 & 5.77 & 5.44 \\
\hline 3 & $0.22 \mathrm{WB}-25 \mathrm{SF}$ & 105 & 100 & 165 & 165 & 1.72 & 6.72 & 6.66 & 5.40 \\
\hline 4 & 0.22B-20SF & 125 & 120 & 205 & 200 & 3.10 & 5.60 & 5.27 & 4.04 \\
\hline 5 & $0.2483 \mathrm{WB}-23.54 \mathrm{SF}$ & 115 & 115 & 200 & 190 & 2.80 & 9.18 & 7.43 & 7.98 \\
\hline 6 & $0.26 \mathrm{WB}-20 \mathrm{SF}$ & 120 & 125 & 250 & 250 & 5.25 & 12.95 & 15.05 & 10.80 \\
\hline 7 & $0.2483 \mathrm{WB}-16.46 \mathrm{SF}$ & 110 & 110 & 150 & 155 & 1.33 & 8.43 & 8.77 & 7.13 \\
\hline 8 & 0.22WB-15SF & 120 & 125 & 210 & 205 & 3.10 & 9.24 & 8.65 & 11.34 \\
\hline 9 & $0.1917 \mathrm{WB}-16.46 \mathrm{SF}$ & 110 & 110 & 175 & 165 & 1.89 & 10.15 & 5.58 & 3.59 \\
\hline 10 & 0.18WB-OSF & 100 & 105 & 130 & 135 & 0.76 & 11.74 & 7.27 & 2.95 \\
\hline 11 & $0.22 \mathrm{WB}-0 \mathrm{SF}$ & 100 & 100 & 160 & 165 & 1.64 & 10.17 & 13.47 & 8.61 \\
\hline 12 & $0.26 \mathrm{WB}-0 \mathrm{SF}$ & 100 & 100 & 165 & 160 & 1.64 & 14.77 & 16.20 & 9.60 \\
\hline
\end{tabular}

Figure 2 presents relative flowability of six key mixtures. The relative flowability $\left(\Gamma_{\mathrm{m}}\right)$ value of the mixture containing a higher amount of SF at the same $\mathrm{WB}$ was lower than those of the mixtures with low SF content. For instance, the $\Gamma_{\mathrm{m}}$ of mixture $0.22 \mathrm{WB}-25 \mathrm{SF}$ containing $25 \% \mathrm{SF}$ was 1.72 , whereas that of mixture $0.22 \mathrm{WB}-15 \mathrm{SF}$ containing $15 \% \mathrm{SF}$ was 3.31 . When the replacement percentage of SF increases and the same amount of SP is used, the reduction of $\Gamma_{\mathrm{m}}$ in the mixture is attributed to the high specific surface area of SF.

Figure 2 also shows the effect of $\mathrm{WB}$ on the $\Gamma_{\mathrm{m}}$. As expected, the $\Gamma_{\mathrm{m}}$ of the mixture containing the same amount of SF was increased as WB was increased. It should be noted that the relatively low $\Gamma_{\mathrm{m}}$ in the plain mixture $0.22 \mathrm{WB}-0 \mathrm{SF}$ is due to the dosage of $1 \% \mathrm{SP}$, which is not like the other mixtures containing $1.5 \% \mathrm{SP}$. 


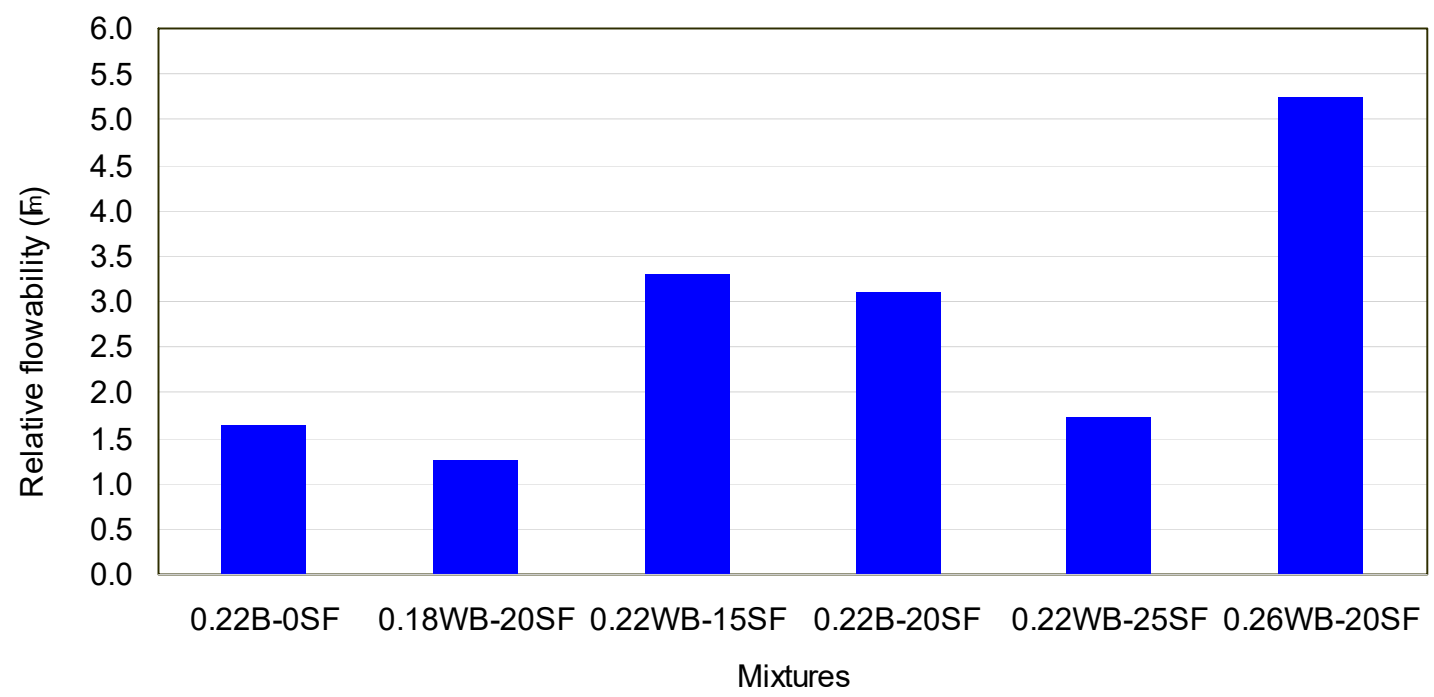

Figure 2. Relative flowability of six key mixtures.

\subsubsection{Penetration Resistance and Setting Time}

The setting time of the RPC mixture was determined using ASTM C403/C403M-16, which is the time required for the penetration resistance (PR) of each mixture to reach $3.44 \mathrm{MPa}$ for the initial set and 27.6 MPa for the final set. Figure 3 presents the PR characteristics of six key RPC mixtures. Similar to the relative flowability results, the SF content and WB influence the PR of the RPC mixture. As the amount of SF in the RPC mixture increases and the WB decreases, the PR increases. For example, Figure 3a shows the effect of SF on the PR. While the PR value of the mixture 0.22WB-25SF containing $25 \% \mathrm{SF}$ was approximately $6.9 \mathrm{MPa}$ at $350 \mathrm{~min}$, the mixture $0.22 \mathrm{WB}-15 \mathrm{SF}$ with $15 \% \mathrm{SF}$ had approximately 3.8 MPa at the same elapsed time. Again, the plain concrete mixture 0.22WB-0SF due to a low dosage of SP had a higher PR value than the RPC mixtures. Moreover, the influence of WB on the PR for the mixture containing $20 \% \mathrm{SF}$ is presented in Figure $3 \mathrm{~b}$. It clearly shows that the PR increases as WB decreases from 0.26 to 0.18 . For instance, the PR values of the mixtures with $W B=0.26,0.22$, and 0.18 at 450 minutes was $6.14 \mathrm{MPa}, 31.99 \mathrm{MPa}$, and $33.65 \mathrm{MPa}$, respectively.

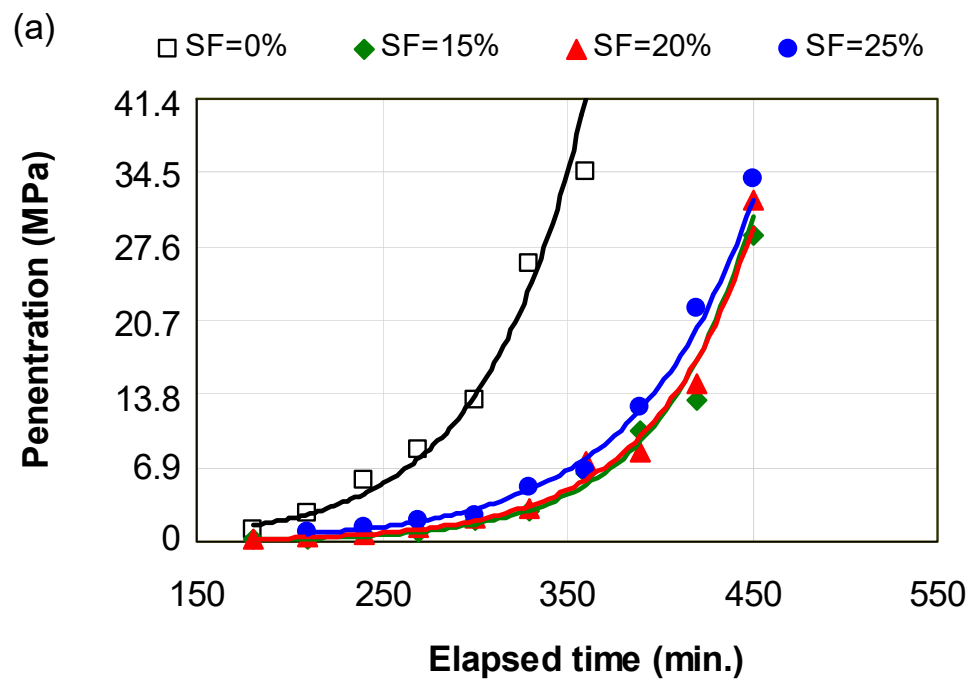

Figure 3. Cont. 


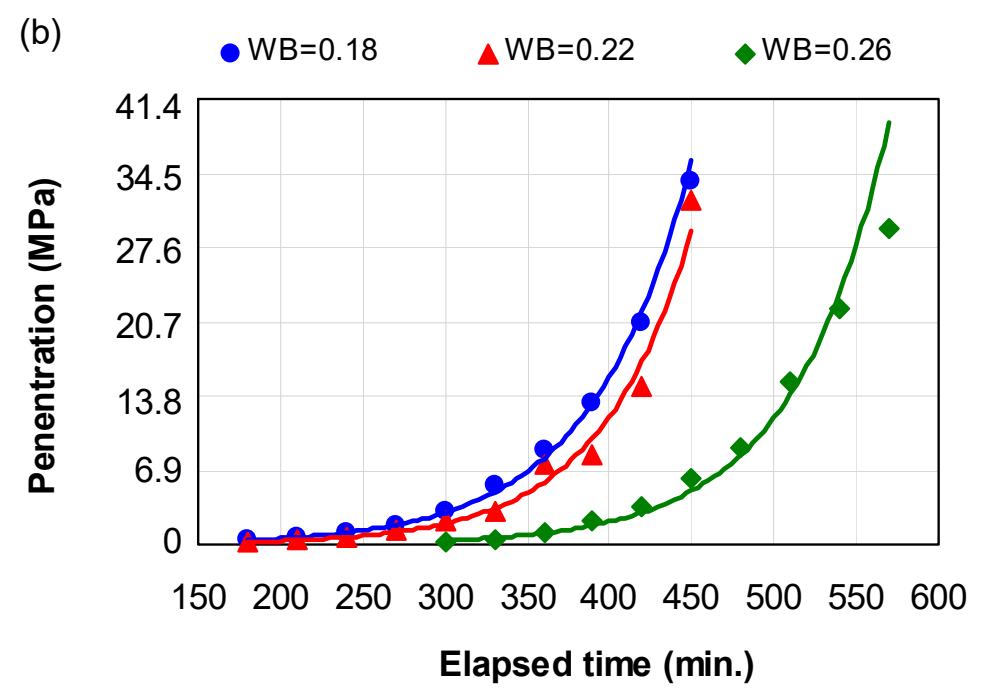

Figure 3. Penetration resistance: (a) effect of SF on penetration resistance (PR) for the mixtures with $\mathrm{WB}=0.22$; (b) effect of $\mathrm{WB}$ on PR for mixtures containing $20 \% \mathrm{SF}$.

As observed from Figure 4a, both the initial and final setting times increased with the increase in WB. While the initial increase of WB from 0.18 to 0.22 has little effect on both the initial and final set time, a further increase of WB from 0.22 to 0.26 produced significant influences on both setting times. It seems that a higher WB plays a more critical role in controlling setting time in RPC mixtures.

Figure $4 \mathrm{~b}$ shows the effect of SF on setting time. At a high SF content, the addition of SF to a binary cement system exhibits the increase in setting time. Lohtia and Joshi [33] reported that the delay in setting time of concrete containing a high amount of SF was attributed to the combined effect of lower cement content and the relatively high dosage of superplasticizers that is needed for the high amount of silica fume that is added to concrete.

On the other hand, Figure $4 \mathrm{~b}$ also shows that changing the SF content has no significant effect on both the initial and final set times, although increasing the SF content slightly decreases the setting time. This result matches with previous findings [34]. Generally speaking, if the optimum amount of SF is used, the addition of SF reduces the setting time, because the pozzolanic reaction of SF is very active at the early hours of hydration [35]. However, at a higher SF content (more than 15\%), the setting time is not influenced by the SF. This could be related to the higher specific surface area of SF. If the RPC needs to achieve the same flowability, it requires an increase in water demand. This water increment is not much different when the SF content is beyond $15 \%[34,36]$.

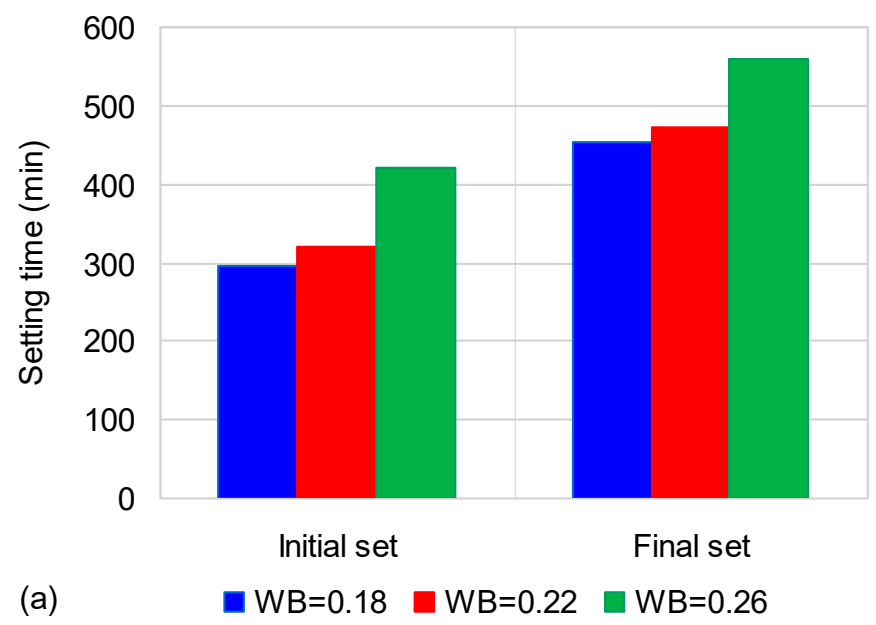

Figure 4. Cont. 


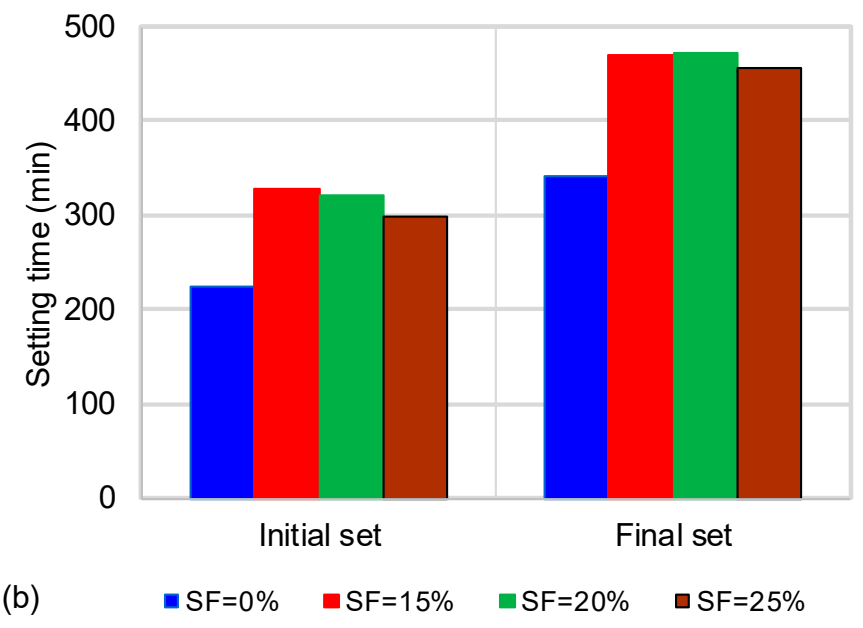

Figure 4. Setting time of key mixtures: (a) effect of changing WB for mixtures containing 20\% SF; (b) effect of changing SF for the mixtures with $\mathrm{WB}=0.22$.

\subsubsection{Relationship between Setting Time and Flowability}

Figure 5 shows the relationship between the relative flowability and the setting time of RPC. Setting time and $\Gamma_{\mathrm{m}}$ are proportional to each other. In other words, the mixture with lower $\Gamma_{\mathrm{m}}$ results in fast setting times, regardless of the initial and final setting times. For instance, while the initial and final setting times of the mixture 0.18WB-20SF with the lowest $\Gamma_{\mathrm{m}}$ of 1.25 are $297 \mathrm{~min}$ and $453 \mathrm{~min}$, respectively, those of the mixture 0.26WB-20SF with the highest $\Gamma_{\mathrm{m}}$ of 5.25 are $420 \mathrm{~min}$ and 558 min, respectively.

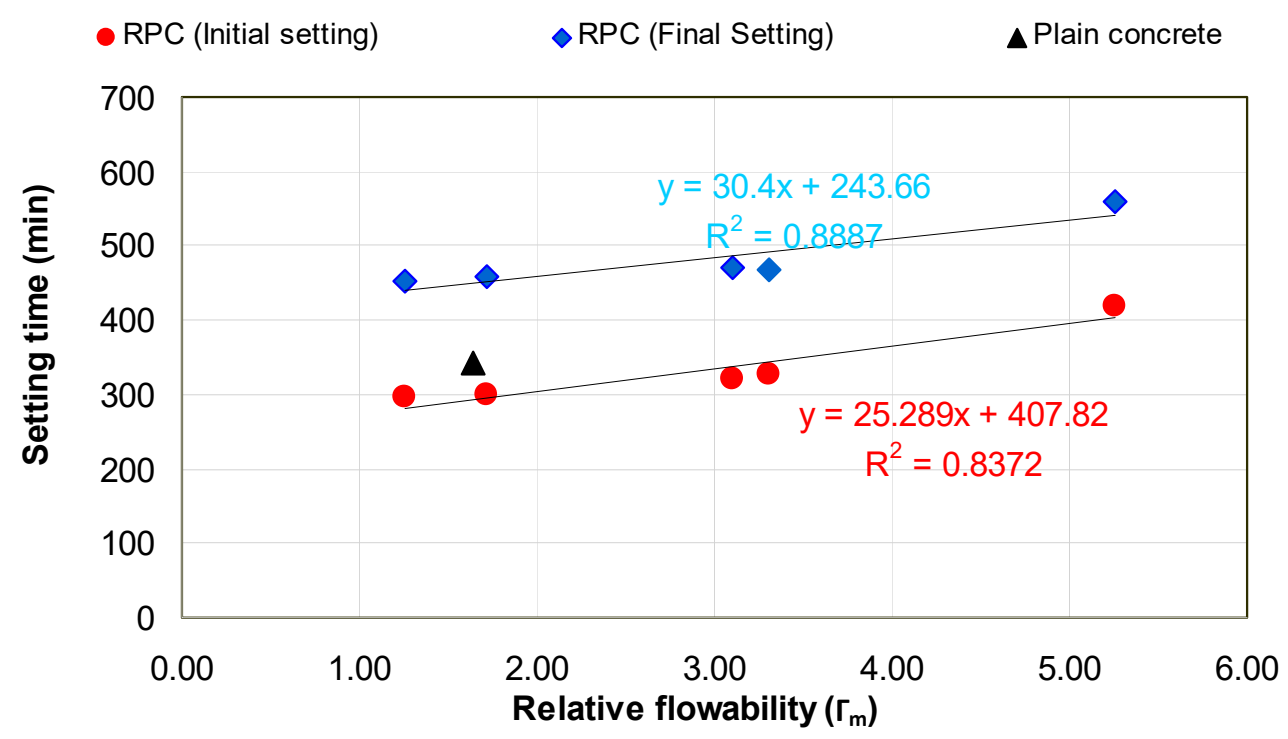

Figure 5. Relationship between setting time and flowability.

\subsection{Hardened Properties of RPC}

\subsubsection{Compressive Strength Development of RPC}

The compressive strength development of all of the RPC mixtures is presented in Figure 6. The compressive strength of RPC varies and depends on the combination of SF content, WB, and SP dosage to adjust flowability. In general, the compressive strength of the RPC mixture was increased with the increase in curing time. However, for mixtures 0.19WB-23.54SF, 0.22WB-25SF, and 0.22WB-15SF, the drop in the compressive strength value at the age of 56 days was observed. It should be noted that 
the permeable porosities of these 56-day samples were higher than those of the 28-day samples, as shown in Table 3. These results indicate that the number of parameters, including WB and SF content, influence the compressive strength development of RPC. The influence of these parameters together with the effect of curing condition will be addressed in the following sections.

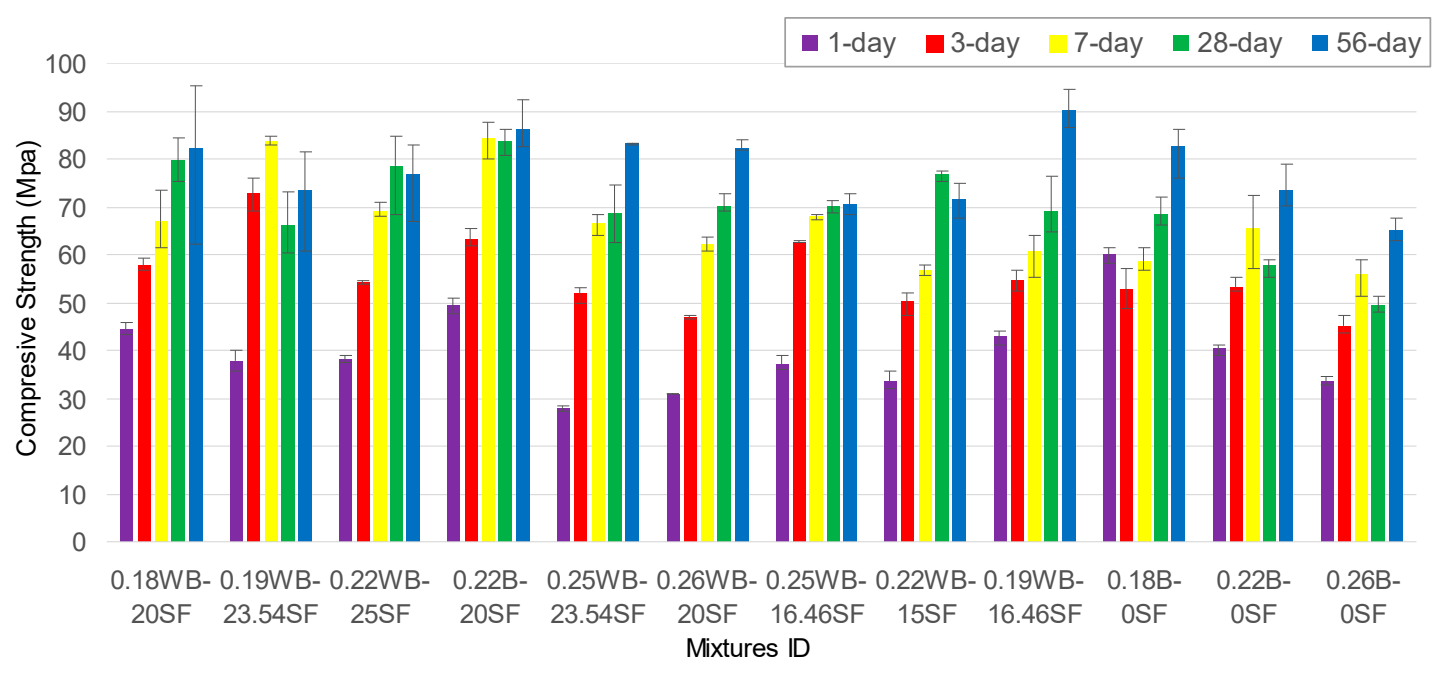

Figure 6. Compressive strength of RPC mixtures.

\subsubsection{Effect of $\mathrm{WB}$ and Curing Temperature on Compressive and Flexural Strength}

Figure 7 illustrates the effect of the WB and curing temperature on the compressive strength for mixtures containing $20 \% \mathrm{SF}$ at all ages. As the WB increased from 0.18 to 0.22 , the compressive strength of the RPC mixture increased, but a further increase of WB from 0.22 to 0.26 led to a significant drop in the compressive strength, except for the 56-day specimen. The reduction of strength over increasing WB can be explained as follows: in general, the porosity of concrete increases with the decrease in the degree of hydration when the WB increases. This means that a higher water content leads to increasing the intensity of pore formation, and eventually decreases the compressive strength of concrete [37]. However, RPC is a special type of concrete containing a relatively higher SF content that increases the water demand of the mixture due to the higher specific surface area of SF. Thus, it seems that decreasing the WB below the certain optimum point results in a decrease of the compressive strength due to the insufficient hydration of the binder inside the concrete.

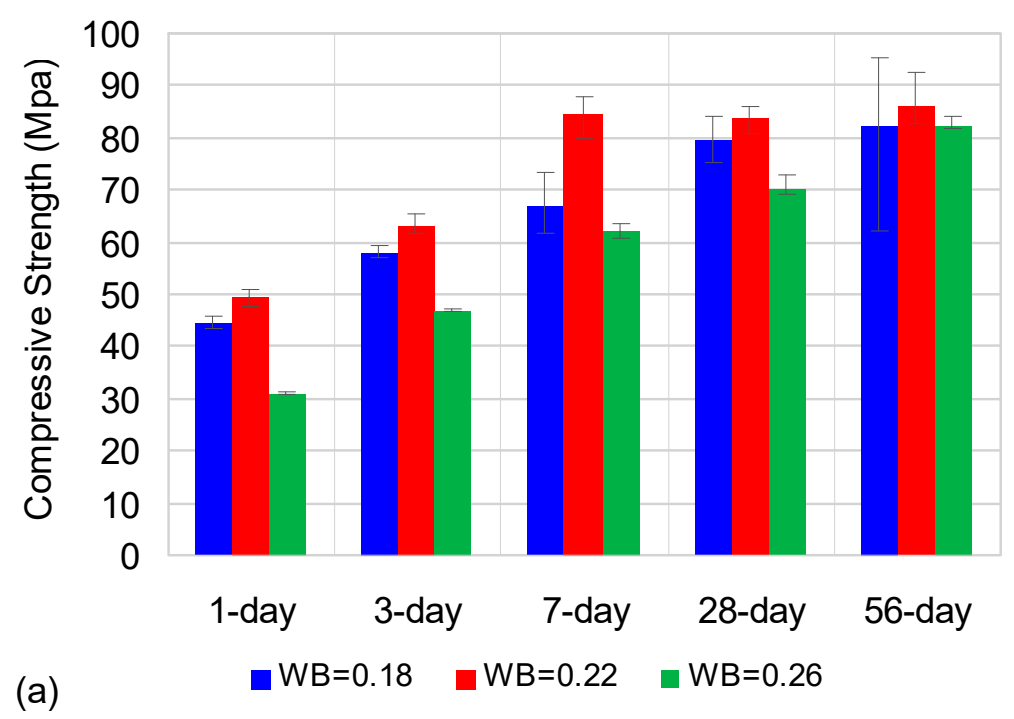

Figure 7. Cont. 


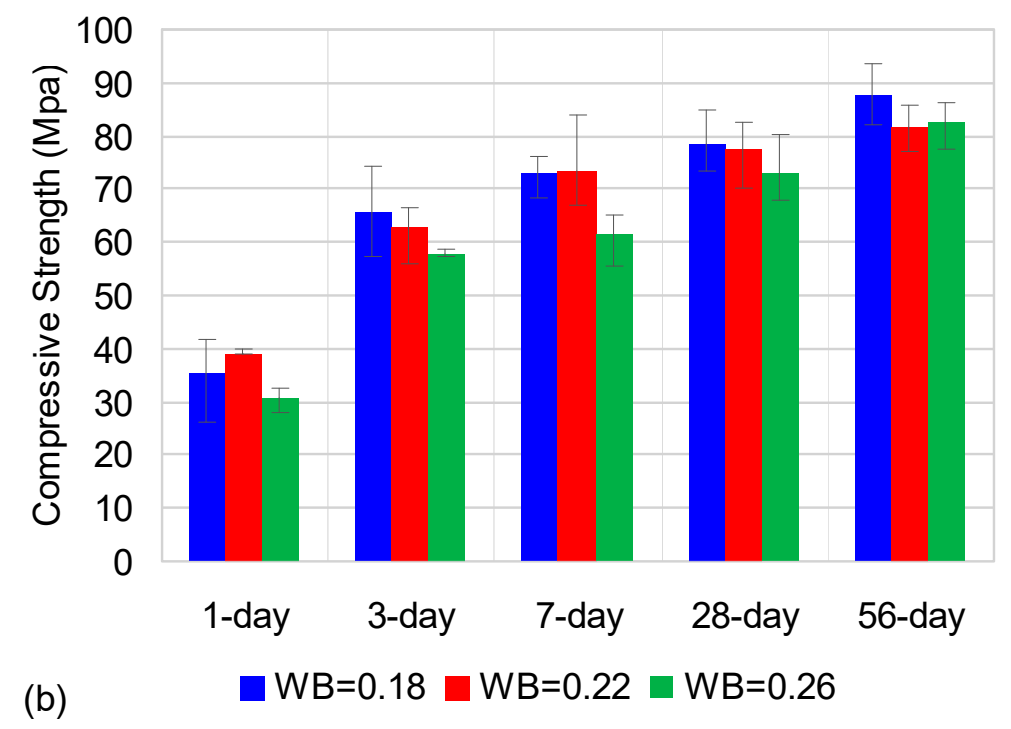

Figure 7. Effect of $\mathrm{WB}$ and curing temperature on compressive strength: (a) $23 \pm 2{ }^{\circ} \mathrm{C}$ and (b) $40 \pm 2{ }^{\circ} \mathrm{C}$.

On the other hand, Figure 7 also shows the effect of curing temperature on the compressive strength of the RPC mixture. During the early stages of curing, the strength of RPC cured at the warm temperature $\left(40 \pm 2{ }^{\circ} \mathrm{C}\right)$ is greater than that of the concrete cured at a normal temperature $\left(23 \pm 2{ }^{\circ} \mathrm{C}\right)$. However, after the age of 7 days, the trend of the compressive strength development of $\mathrm{RPC}$ is reversed. This is the so-called 'crossover effect', which indicates that a higher initial temperature results in a more than proportional increase in the initial rate of hydration, but leads to lower strength at a later age. Verbeck and Helmuth [38] explained that low permeable hydration products built up around the cement particles do not have time to become uniformly distributed within the pores of the hardening paste with rapid hydration. This nonuniform distribution of low-permeable hydration products not only leads to larger pores that reduce the strength, it also hinders the further hydration of the unhydrated cement particles at later ages. Therefore, higher early-age temperature curing results in higher early strength and lower long-term strength.

As shown in Figure 8, the 28-day flexural strength of RPC shows the same trends as for the compressive strength. For normal temperature curing, when the WB increased from 0.18 to 0.22 , the flexural strength of the RPC mixture increased, but a further increase of the WB from 0.22 to 0.26 led to a strength drop. For warm temperature curing, the flexural strength of RPC mixtures generally decreased as the WB increased. Therefore, higher early-age temperature curing leads to higher early flexural strength and lower long-term flexural strength.

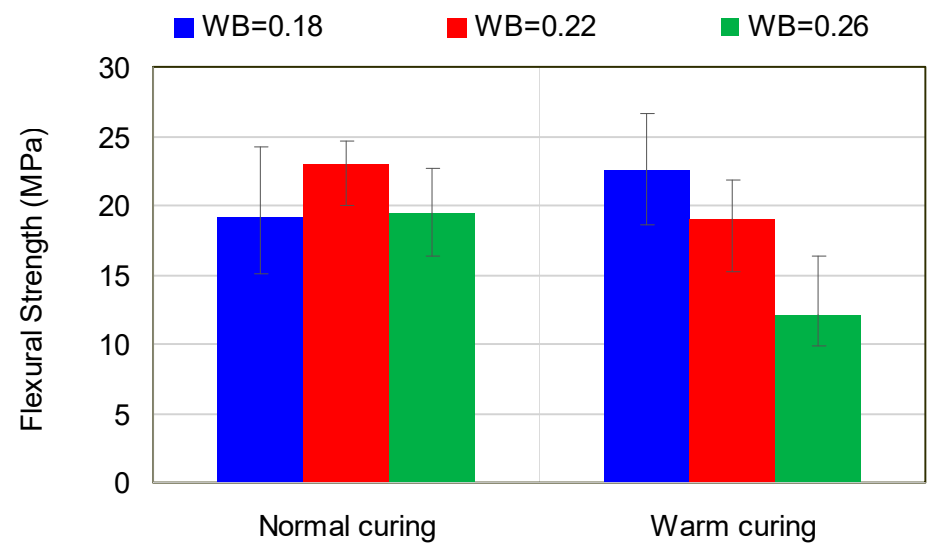

Figure 8. Effect of WB and curing temperature on flexural strength. 


\subsubsection{Effect of SF and Curing Temperature on Compressive and Flexural Strength}

The effect of SF content on the compressive strength is presented in Figure 9. A similar trend has been observed for all of the curing periods, regardless of the curing temperature: increasing the SF content from $15 \%$ to $20 \%$ results in an increase in the compressive strength of RPC. However, further increasing the SF content from $20 \%$ to $25 \%$ drops the compressive strength down. This implies that the addition of SF improves the compressive strength of RPC up to a certain optimum point, but a further increase in the SF content does not result in additional strength gain. It is possible to state that the optimum amount of SF induces a strong bonding between the cement paste and the aggregate due to the filler packing effect and the pozzolanic reaction of SF. This enhanced adhesion results in a much stronger transition zone, and thus leads to a more even distribution of stresses within the concrete volume, and ultimately to larger compressive strength. However, the addition of an excessive amount of SF to the mixture does not provide continuous strength development because of the limited pozzolanic reaction. When the WB is kept constant, an increase in the SF content results in a situation where the silicates are in excess, and the $\mathrm{CH}$ produced by cement hydration is deficient. Hence, there is no more pozzolanic reaction that produces calcium silicate hydrate (C-S-H) lattice forms related to strength development. The other possible reason to bring the decrease of compressive strength is that the addition of an excessive amount of SF to the mixture may cause an incompatibility issue (interactions between acceptable materials that result in unexpected or unacceptable performance). Therefore, further investigation is required in order to identify this result.
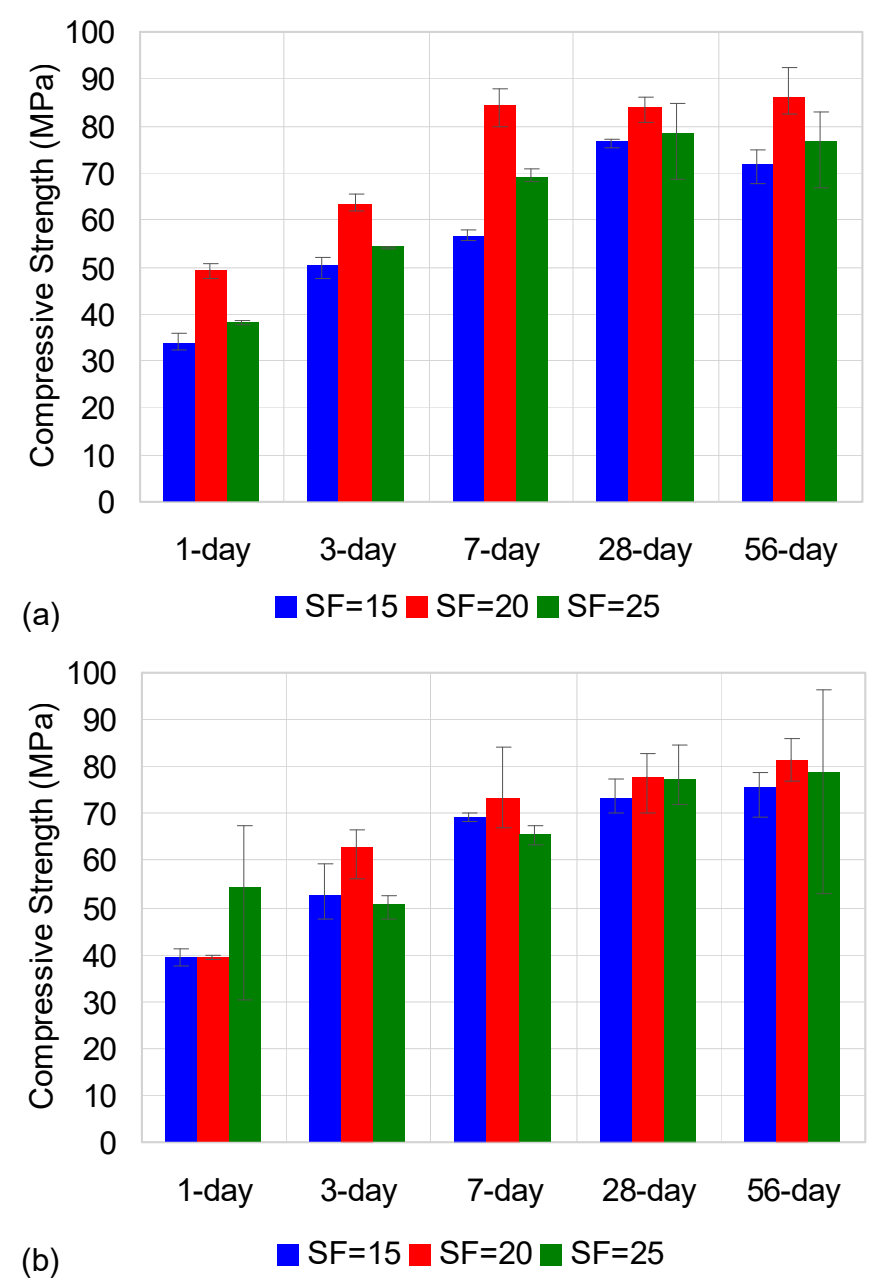

Figure 9. Effect of the $\mathrm{WB}$ and curing temperature on compressive strength at $\mathrm{WB}=0.22:(\mathbf{a}) 23 \pm 2{ }^{\circ} \mathrm{C}$ and (b) $40 \pm 2{ }^{\circ} \mathrm{C}$. 
Furthermore, the compressive strength of RPC increases with age, but the increase in compressive strength up to 7 days is more significant when compared to that at 56 days. Hence, the addition of SF beyond a certain amount to the RPC mixture has no significant effect on strength development.

Figure 10 shows the 28-day flexural strength of RPC. Similar to the compressive strength results, when the SF content increased from $15 \%$ to $20 \%$, the flexural strength of the RPC mixture increased, but a further increase of SF content up to $25 \%$ led to strength drop. Interestingly, no typical trend was observed for warm temperature curing, but this can be explained by the porosity to density ratio $(P / D)$ : the lower the $P / D$, the higher the flexural strength. As presented in Table 4, the mixture with low flexural strength has a higher porosity and lower density. For example, while the porosity and density of the mixture containing $15 \% \mathrm{SF}$ are $8.16 \%$ and $2.24 \mathrm{~g} / \mathrm{cm}^{3}$, those properties of the mixture containing $20 \% \mathrm{SF}$ are $11.35 \%$ and $2.20 \mathrm{~g} / \mathrm{cm}^{3}$, respectively. In other words, the P/D of the former is 3.65 , and the $\mathrm{P} / \mathrm{D}$ of the latter is 5.15 .

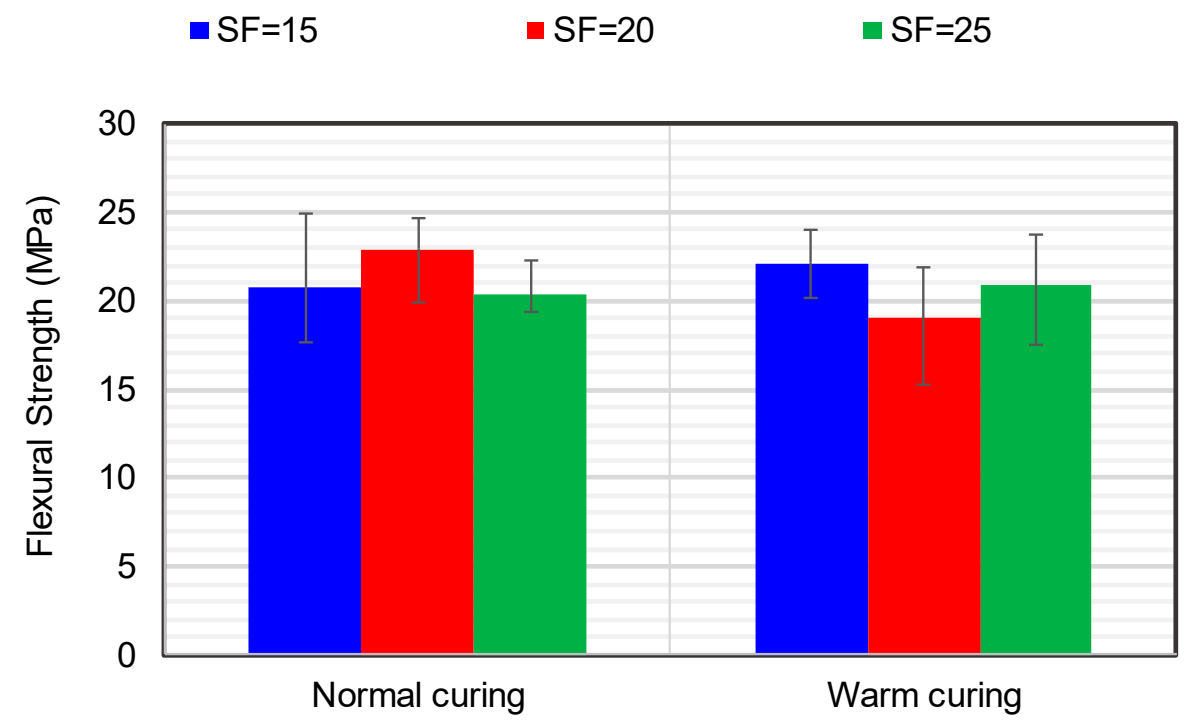

Figure 10. Effect of SF and curing temperature on flexural strength.

Table 4. Density and porosity test results.

\begin{tabular}{cccccccc}
\hline No. & Mixture & \multicolumn{2}{c}{ Density $\left(\mathbf{g} / \mathbf{c m}^{\mathbf{3}}\right)$} & \multicolumn{2}{c}{ Porosity } & \multicolumn{2}{c}{ Porosity/Density } \\
\hline & & $\begin{array}{c}\text { Normal } \\
\text { Curing }\end{array}$ & $\begin{array}{c}\text { Warm } \\
\text { Curing }\end{array}$ & $\begin{array}{c}\text { Normal } \\
\text { Curing }\end{array}$ & $\begin{array}{c}\text { Warm } \\
\text { Curing }\end{array}$ & $\begin{array}{c}\text { Normal } \\
\text { Curing }\end{array}$ & $\begin{array}{c}\text { Warm } \\
\text { Curing }\end{array}$ \\
\hline 1 & 0.18 WB-20SF & 2.23 & 2.19 & 4.14 & 5.75 & 1.85 & 2.62 \\
2 & 0.22 WB-OSF & 2.26 & 2.24 & 13.47 & 13.10 & 5.95 & 5.84 \\
3 & 0.22 WB-15SF & 2.21 & 2.24 & 8.65 & 8.16 & 3.92 & 3.65 \\
4 & $0.22 \mathrm{~B}-2$ SSF & 2.17 & 2.20 & 5.27 & 11.35 & 2.43 & 5.15 \\
5 & $0.22 \mathrm{WB}-25 \mathrm{SF}$ & 2.19 & 2.18 & 6.66 & 10.73 & 3.03 & 4.92 \\
6 & $0.26 \mathrm{WB}-20 \mathrm{SF}$ & 2.18 & 2.20 & 15.05 & 13.30 & 6.89 & 6.04 \\
\hline
\end{tabular}

Note: * Porosity of RPC was measured according to ASTM C 642-13 Standard Test Method for Density, Absorption, and Voids in Hardened Concrete.

\subsubsection{Drying Shrinkage of RPC}

The drying shrinkage characteristics of a plain concrete mixture and RPC mixture containing $20 \%$ SF are illustrated in Figure 11. As expected, for one-day air curing (Figure 11a), plain concrete has less drying shrinkage than RPC. It is well known that the drying shrinkage of concrete relies on cementitious material content, water content, paste content, sand content, water permeable porosity, and strength level [39]. The higher the paste content of concrete, the higher the drying shrinkage. It was calculated that the volumetric paste contents of plain concrete and an RPC mixture 0.22WB-20SF from Table 1 are $0.672 \mathrm{~m}^{3}$ and $0.647 \mathrm{~m}^{3}$, respectively. Thus, the higher value of the drying shrinkage of $\mathrm{RPC}$ is due to the higher paste content. 
However, for seven-day moist curing (Figure 11b), RPC has lower drying shrinkage than plain concrete, despite its higher paste content. This result may be attributed to the strength and water permeable porosity of the concrete. Regarding strength, the 7-day average strength of the RPC is about 84.563 MPa in comparison to $65.5 \mathrm{MPa}$ for plain concrete, which is a difference of approximately $20 \mathrm{MPa}$. $\mathrm{SF}$ could refine the pore structure and improve the early strength. This enhanced microstructure of RPC produces less water permeable capillary voids, which play a critical role in drying shrinkage. The less the capillary void content of the concrete, the lower the drying shrinkage. This is confirmed by the porosity result shown in Table 4.
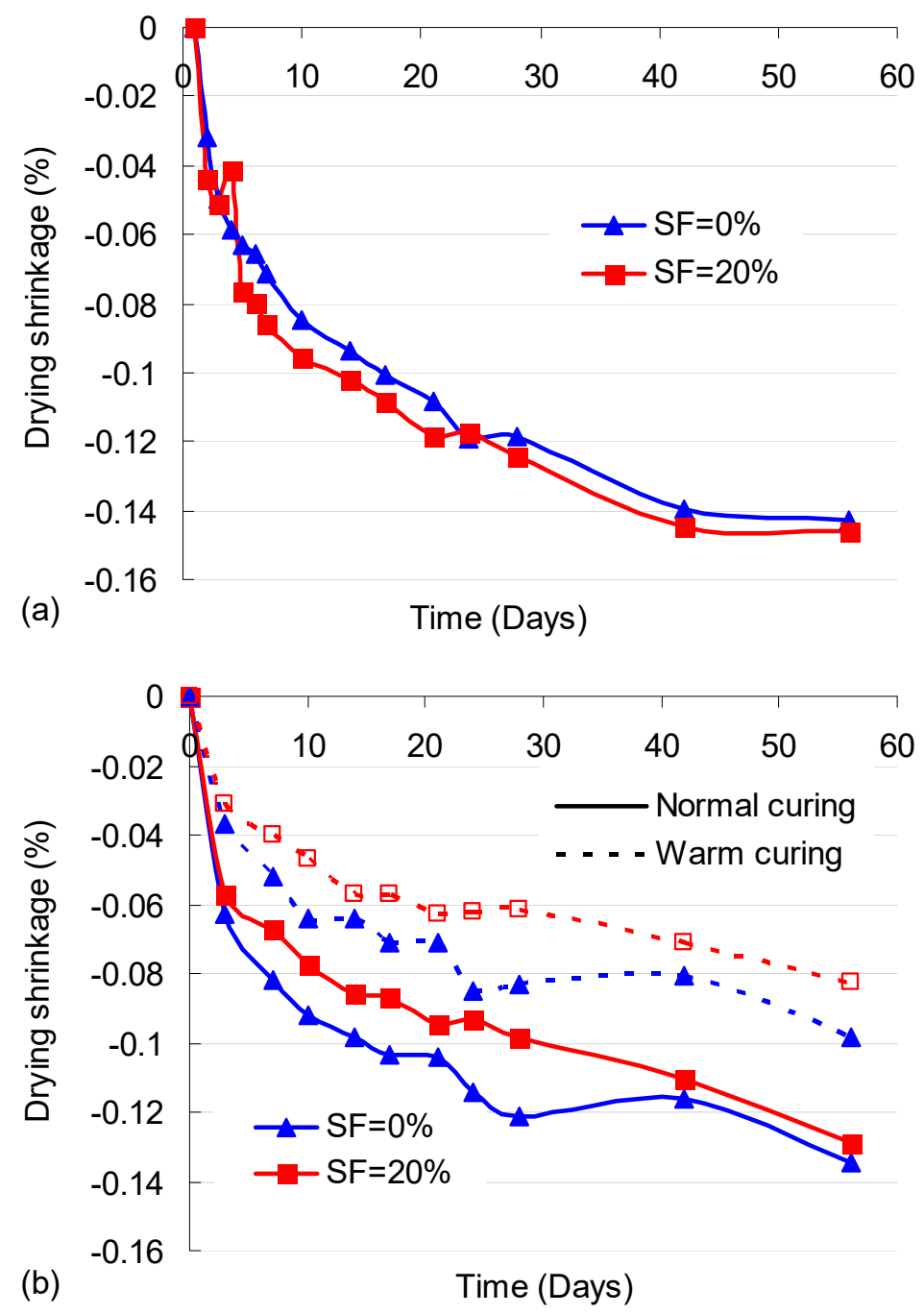

Figure 11. Drying shrinkage of plain concrete and RPC: (a) one-day air curing; (b) seven-day moist curing.

\subsubsection{Effect of WB and Curing Temperature on Drying Shrinkage}

Figure 12 shows the effect of the WB and curing temperature on drying shrinkage for one-day air-cured and seven-day moist-cured specimens. Increasing the WB tends to increase the drying shrinkage in RPC, regardless of the curing regime. This is possibly because at a higher WB, more pores are formed inside the concrete structure. As a result, the evaporation of the water from the pores combined with the formation of microcracks along the interconnected pores leads to higher drying shrinkage. This is confirmed by the porosity results shown in Table 4 . For example, while the porosity and density of the normal temperature cured RPC mixture with a WB $=0.18$ are $4.14 \%$ and $2.23 \mathrm{~g} / \mathrm{cm}^{3}$, those properties of the mixture having a $\mathrm{WB}=0.26$ are $15.05 \%$ and $2.18 \mathrm{~g} / \mathrm{cm}^{3}$, respectively. In other 
words, the $\mathrm{P} / \mathrm{D}$ of the former is 1.85 , while the $\mathrm{P} / \mathrm{D}$ of the latter is 6.89 . The lower value of the $\mathrm{P} / \mathrm{D}$ indicates that the RPC has less the capillary void content and less capillary water, which is associated with drying shrinkage.

Figure $12 \mathrm{~b}$ also shows that warm temperature curing tends to decrease the drying shrinkage of RPC significantly. This may be attributed to the formation of low permeable hydration products being built up around the cement particles. As stated previously, low-permeable hydration products are built up around the cement particles rapidly when the RPC is cured at a warm temperature. These low permeable hydration products lead to larger pores, but prevent the evaporation of water through these hydration products. In turn, higher early-age temperature curing results in higher early strength and lower drying shrinkage.

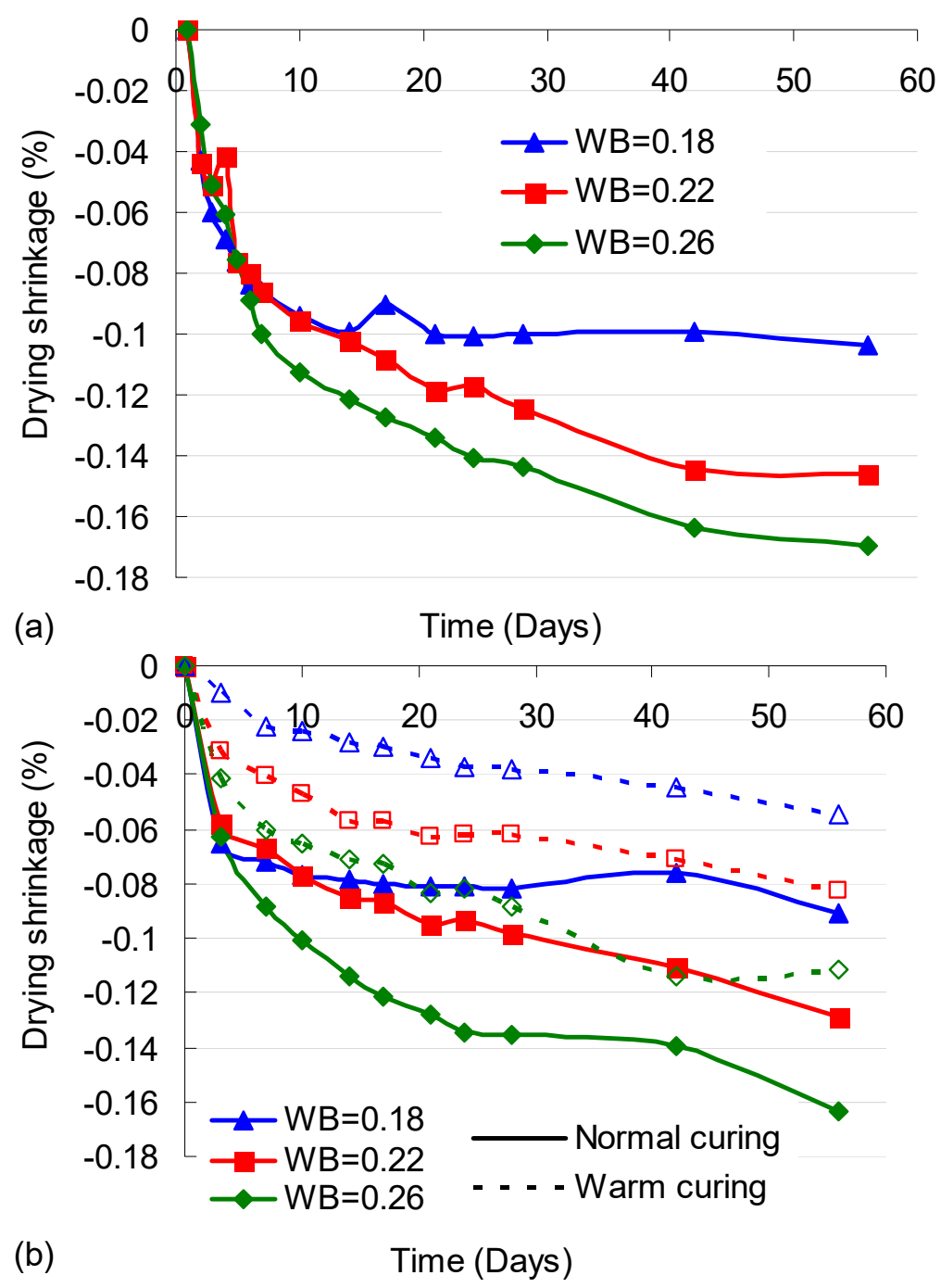

Figure 12. Effect of the WB on drying shrinkage of RPC: (a) one-day air curing; (b) seven-day moist curing.

\section{Discussion}

\subsection{Optimization of the RPC Mix Design Component}

Minitab software was used to perform RSM analysis to identify the combined effect of the WB and SF content change on the compressive strength of RPC for each curing period. As shown in Figure 13, both the SF content and the WB influence the compressive strength of RPC. Contour plots clearly present that the strength response surface possesses a dark green color area, and the light green colored area and grey colored area indicate high strength and low strength, respectively. For 
instance, as shown in Table 2, the mixture 0.22WB-20SF with coded values of WB (0) and SF (0) is located in the darkest green area in the 7-day contour plot. The area under this intersection represents the compressive strength value of $84.5 \mathrm{MPa}$, which indicates the highest compressive strength. On the other hand, the mixture $0.22 \mathrm{WB}-15 \mathrm{SF}$ with coded values of WB (0) and SF (-1.4142) has a very light green color, which indicates the lowest compressive strength. This trend is the same in the 28-day and 56-day contour plots.

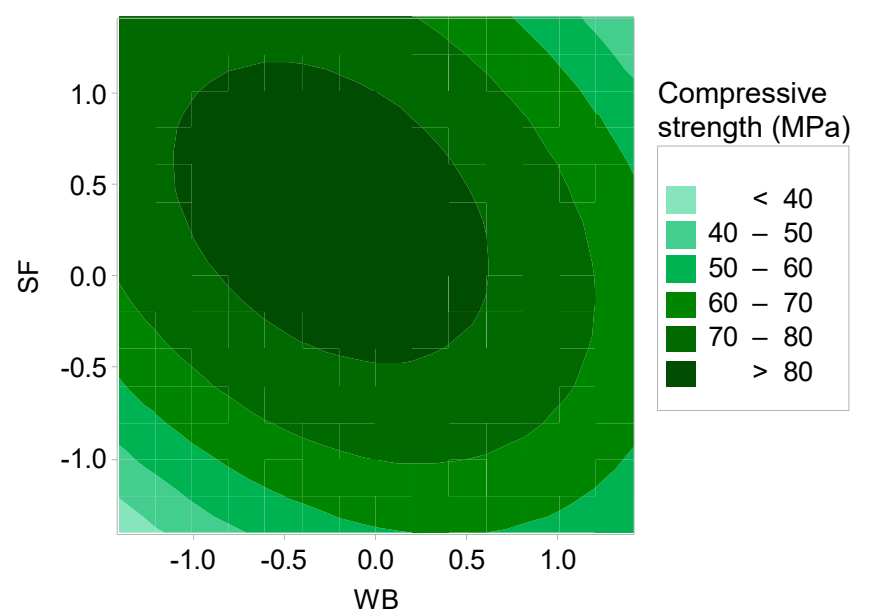

(a)

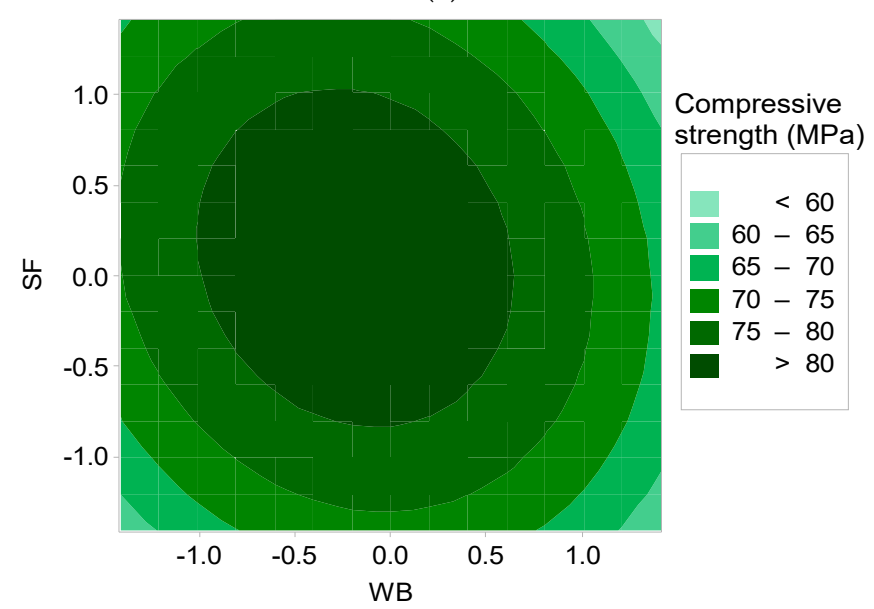

(b)

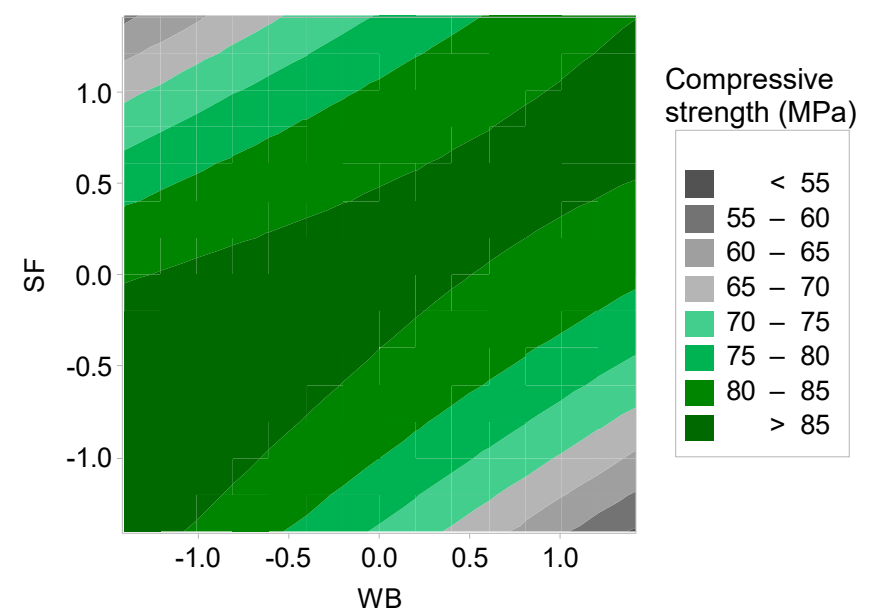

(c)

Figure 13. Contour plots for combined effect of WB and SF (\%) on compressive strength: (a) 7-day plot; (b) 28-day plot; (c) 56-day plot. 
Minitab software was also used to perform quadratic regression analysis for the compressive strength of RPC. Equations 6-8 indicate the modeling equations of the effect of the WB and SF on 7-day, 28-day, and 56-day compressive strengths. The accuracy of the model was evaluated based on the $\mathrm{R}^{2}$ values for each age. Figure 14 shows the regression analysis results. As shown in Figure 14, the $\mathrm{R}^{2}$ values for the 7-day, 28 -day, and 56-day compressive strengths are $89.81 \%, 63.52 \%$, and $91.66 \%$, respectively. The variation of $R^{2}$ values at different ages may be associated with the pozzolanic reaction of the SF. While the hydration of cement mainly dominates the early age strength development of RPC, the pozzolanic reaction, which reacts with calcium hydroxide $(\mathrm{CH})$ to form $\mathrm{C}-\mathrm{S}-\mathrm{H}$, fully charges the strength development at 56 days. This cement hydration and pozzolanic reaction respond to high $\mathrm{R}^{2}$ values at both ages ( 7 days and 56 days). The relatively low $R^{2}$ value at 28 days may be attributed to the transition period of the ongoing pozzolanic reaction. It should be noted that all of the RPC mixtures that are used for RSM analysis were cured at a normal temperature $\left(23 \pm 2{ }^{\circ} \mathrm{C}\right)$, which provide a relatively slow pozzolanic reaction.

$$
\begin{aligned}
& f_{c 7-\text { day }}=84.52-2.03 W B+4.92 S F-8.42 W B^{2}-9.36 S F^{2}-6.10 W B \times S F \\
& f_{c 28-\text { day }}=83.77-2.04 W B+0.68 S F-5.90 W B^{2}-4.62 S F^{2}-1.33 W B \times S F \\
& f_{c 56-\text { day }}=86.10-1.28 W B+0.36 S F-1.71 W B^{2}-5.65 S F^{2}+7.428 W B \times S F
\end{aligned}
$$

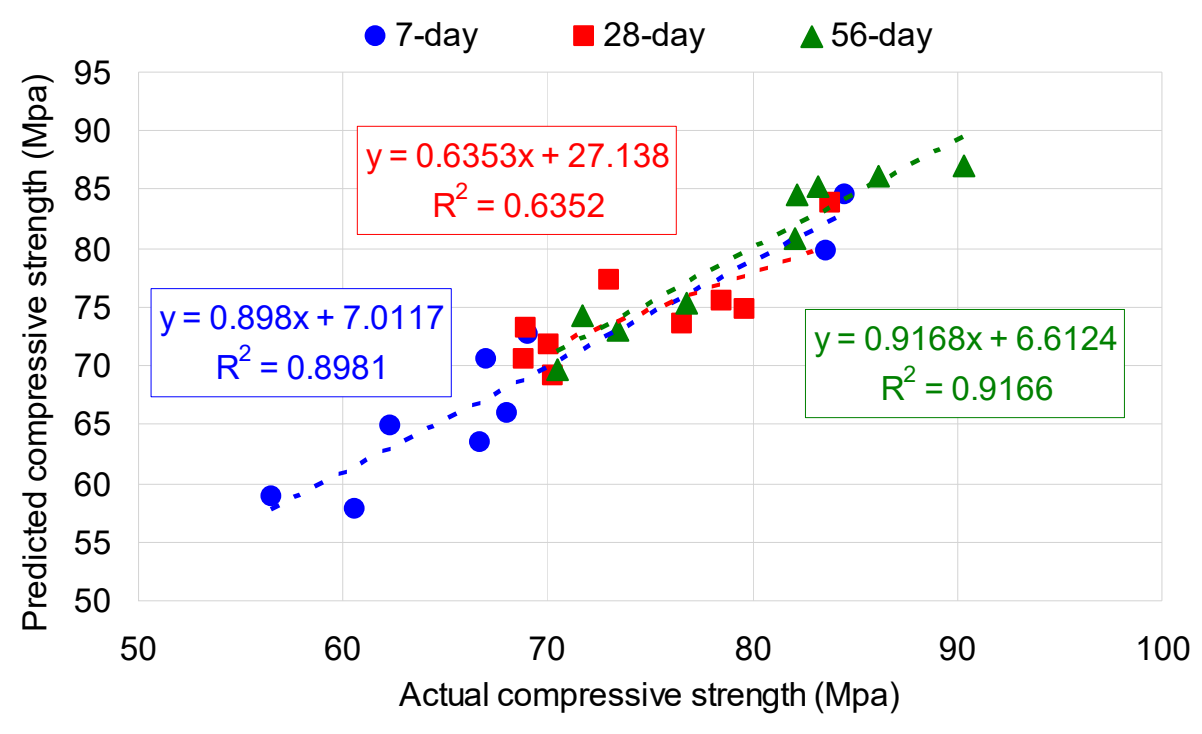

Figure 14. Regression analyses for predicted vs. actual strength values.

Based on the RSM modeling, the coded values of WB and SF that are required to achieve the highest compressive strength at the age of 7 days, 28 days, and 56 days were determined to be $(-0.2428$, $0.3286),(-0.1857,0.1)$, and $(-1.4142,-0.9)$, respectively. These values respond $(0.213,21.16),(0.215$, 20.35), and $(0.180,16.81)$ at the ages of 7 days, 28 days, and 56 days, respectively. While the first term refers to the $\mathrm{WB}$, the second term indicates the SF content. Furthermore, the coordination of the $\mathrm{WB}$ and SF resulting in the highest strength $(84.91 \mathrm{MPa})$ for the combined ages is $(-0.2428,0)$ which indicates that the $\mathrm{WB}=0.213$ and $\mathrm{SF}=20.0 \%$. This combination is similar to the tested mixture design of the $\mathrm{WB}=0.22$ and $\mathrm{SF}=20 \%$, having an average strength of $84.80 \mathrm{MPa}$.

\subsection{Comparison of Test Results and Analytical Simulations}

In a parallel research study, the structural response and demand of the concrete pile under high pressure originated from the energy storage was investigated through finite element modeling and simulations. The study covered two structural design parameters, including the number of building 
stories and pile inner diameters. A full description of the study can be found in Zhang et al. [26]. As observed in the study, the concrete pile as an energy storage medium was subjected to considerable high circumferential tensile stresses, which might result in cracking and air pressure leakage in normal-strength concrete. Thus, it is important to ensure that the tensile strength of the RPC tested in this paper is higher than the maximum tensile stress demand obtained from the simulations.

Figure 15 compares the maximum tensile stress demand and the tensile strength of the RPC. The maximum tensile stress demands in the pile, which are plotted as solid lines, were obtained from the simulations for different design cases by varying number of stories (2-story, 6-story, and 10-story buildings) and the inner diameters of the piles. The tensile strength that was calculated based on the test results is plotted as horizontal dotted trend lines for (a) different SF contents (at WB $=0.22$ ) and (b) different $\mathrm{WB}$ (at $\mathrm{SF}=20 \%$ ). The tensile strength was calculated by dividing the 28-day normal curing flexural strength (refer to Figures 8 and 10) by a factor of 2.5, as proposed in Kim and Tahah [40]. As seen in Figure 15, the RPCs that are studied in this paper generally have higher tensile strength than the maximum circumferential tensile stress demand obtained from the simulations, which indicates that the RPC is potentially suitable for the energy storage pile application. The mixture design with a combination of $\mathrm{WB}=0.22$ and $\mathrm{SF}=20 \%$ provides the highest tensile strength of the RPC.
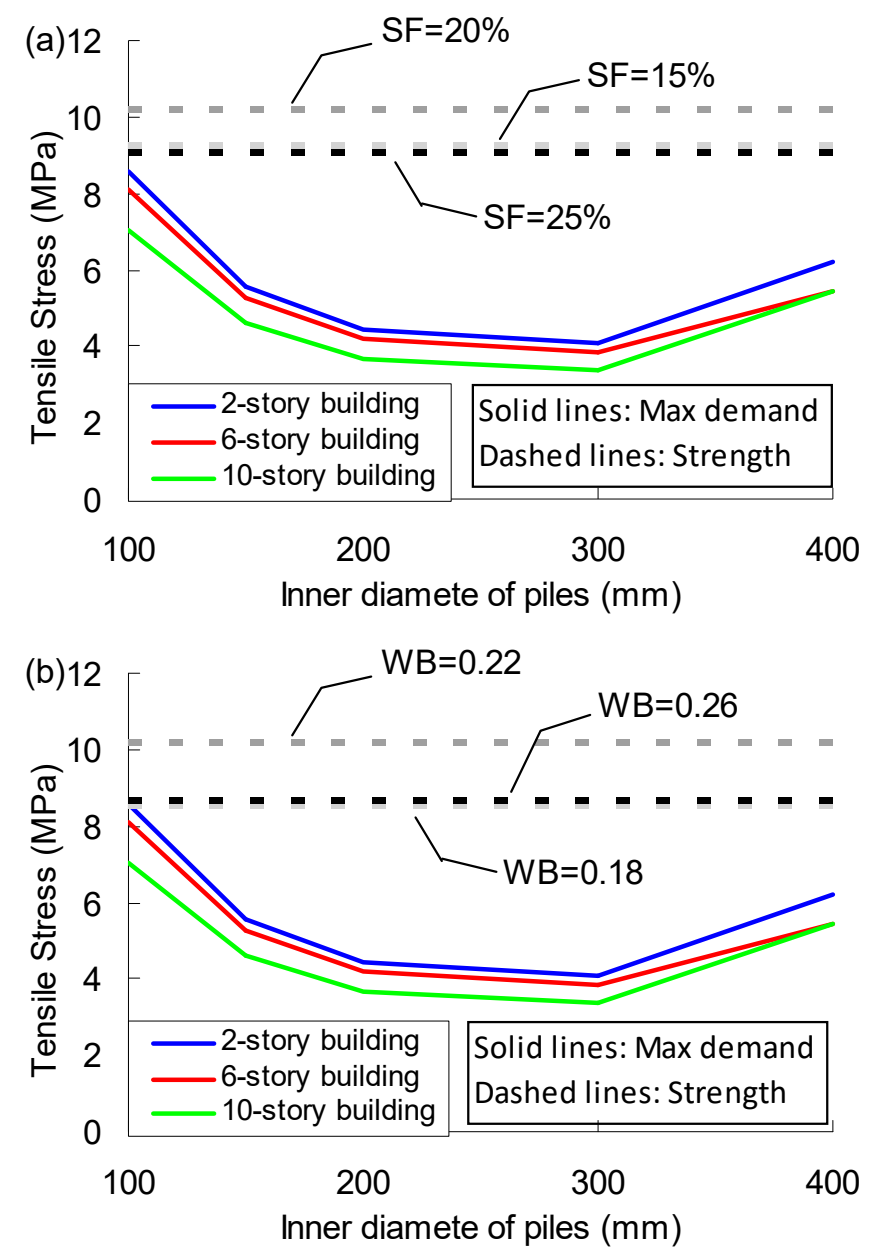

Figure 15. Test and simulation results comparisons: (a) different SF content; (b) different WB.

\section{Conclusions}

RPC is a newly emerging and promising concrete material. It has an improved microstructure that results in higher compressive and flexural strengths and better durability. This research focused on the optimization of mixture parameters (WB and SF) to achieve the RPC with high compressive, 
flexural strengths, and low drying shrinkage under normal and warm temperature curing conditions. The following conclusions were drawn based on the experiments and analysis results:

(1) Except for a plain mixture (0.22WB-0SF) with a relative lower SP content (1\%), the relative flowability of RPC decreased as the SF content increased for the mixtures with a constant WB. At the same time, the relative flowability of RPC decreased as the WB decreased for the mixtures with constant SF content.

(2) For the RPC with a certain amount of SF, the penetration resistance increased as the SF content increased for mixtures with constant WB. For a fixed SF content, the penetration resistance increased as the WB decreased.

(3) Both the initial and final setting times increased with the increase in the WB, but a higher WB plays a more critical role in controlling the setting time in the RPC mixture. At a high dosage of SF content, a further increase of SF content has no significant effect on both the initial and final set times, although increasing the SF content slightly decreases setting.

(4) As the WB increased from 0.18 to 0.22 , the compressive and flexural strengths of the RPC mixture increased, but a further increase of WB from 0.22 to 0.26 led to a significant drop in both strengths.

(5) During the early age of curing, the compressive and flexural strengths of the RPC cured at the warm temperature are greater than that of concrete cured at a normal temperature. However, after the age of 7 days, the strength development trend of RPC became reversed.

(6) Increasing the SF content from $15 \%$ to $20 \%$ increased the compressive and flexural strengths of RPC. Further increasing the SF content from $20 \%$ to $25 \%$ decreased the strength.

(7) For one-day air-curing condition, plain concrete has less drying shrinkage than RPC. However, for seven-day moist-curing conditions, RPC has less drying shrinkage than plain concrete, despite its higher paste content.

(8) Based on the RSM analysis, the optimum WB and SF content to achieve the highest strength was determined to be $\mathrm{WB}=0.213$ and $\mathrm{SF}=20.0 \%$, and the corresponding compressive strength was $84.91 \mathrm{MPa}$. This combination is similar to the tested mixture design of the $\mathrm{WB}=0.22$ and $\mathrm{SF}=20 \%$, which had an average strength of $84.80 \mathrm{MPa}$.

(9) The RPC studied in this paper generally has a tensile strength that is higher than the maximum circumferential tensile stress demand generated from air pressure in the energy storage pile. It indicates that the RPC is potentially suitable for the energy storage pile application, since the considerable high tensile stress is a major concern for the safety of the pile.

In order to conclusively state all of the findings explained above and to validate the overall response model, it is necessary to conduct a series of experiments using the optimized mix proportions and select some percentage variables (WB and SF content). The measurement of the compressive and flexural strengths and drying shrinkage will be needed under different curing regimes. Such further experimental works can confirm the findings obtained from this study.

Author Contributions: Data curation, U.B. and E.S.; Formal analysis, U.B. and E.S.; Funding acquisition, D.Z. and J.R.K.; Investigation, C.-S.S. and D.Z.; Methodology, C.-S.S. and D.Z.; Project administration, J.R.K.; Supervision, C.-S.S. and D.Z.; Visualization, U.B.; Writing-original draft, U.B.; Writing-review \& editing, C.-S.S., D.Z. and J.R.K.

Funding: This research was supported by the Nazarbayev University Research Fund under Grant (\#SOE2017001) "Development of a Renewable Energy Storage System using Reinforced Concrete Foundations." The authors are grateful for this support. Any opinions, findings, and conclusions or recommendations expressed in this material are those of the author(s) and do not necessarily reflect the views of the Nazarbayev University.

Acknowledgments: The authors would like to thank Aidana Tleuken, Almas Sheriyev, Nariman Karatay, and Islam Mukhammedrakhym, undergraduate students at Nazarbayev University for their assistance in the laboratory work.

Conflicts of Interest: The authors declare no conflict of interest. 


\section{References}

1. Richard, P.; Cheyrezy, M. Composition of reactive powder concretes. Cem. Concr. Res. 1995, 25, $1501-1511$. [CrossRef]

2. Sun, H.; Li, Z.; Memom, S.A.; Zhang, Q.; Wang, Y.; Liu, B.; Xu, W.; Xing, F. Influence of Ultrafine $2 \mathrm{CaO}$ SiO2 Powder on Hydration Properties of Reactive Powder Concrete. Materials 2015, 8, 6195-6207. [CrossRef]

3. Chan, Y.W.; Chu, S.H. Effect of silica fume on steel fiber bond characteristics in reactive powder concrete. Cem. Concr. Res. 2004, 34, 1167-1172. [CrossRef]

4. Beglarigale, A.; Yazici, H. Pull-out behavior of steel fiber embedded in flowable RPC and ordinary mortar. Constr. Build. Mater. 2015, 75, 255-265. [CrossRef]

5. Ahmad, S.; Zubair, A.; Maslehuddin, M. Effect of key mixture parameters on flow and mechanical properties of reactive powder concrete. Constr. Build. Mater. 2015, 99, 73-81. [CrossRef]

6. Tam, C.M.; Tam, V.W.Y.; Ng, K.M. Optimal conditions for producing reactive powder concrete. Mag. Concr. Res. 2010, 62, 704-716. [CrossRef]

7. Ji, T.; Chen, B.; Zhuang, Y.; Li, F.; Huang, Z.; Liang, Y. Effects of sand particle size and gradation on strength of reactive powder concrete. Adv. Mater. Res. 2011, 261-263, 208-211. [CrossRef]

8. Abbas, S.; Nehdi, M.L.; Saleem, M.A. Ultra-high performance concrete: Mechanical erformance, durability, sustainability and implementation challenges. Int. J. Concr. Struct. Mater. 2016, 10, 271-295. [CrossRef]

9. Vagelis, G.P. Experimental investigation and theoretical modeling of silica fume activity in concrete. Cem. Concr. Res. 1999, 29, 79-86.

10. Wang, D.; Shi, C.; Wu, Z.; Xiao, J.; Huang, Z.; Fang, Z. A review on ultra high performance concrete: Part II. Hydration, microstructure and properties. Constr. Build. Mater. 2015, 96, 368-377. [CrossRef]

11. Yu, R.; Spiesz, P.; Brouwers, H.J.H. Mix design and properties assessment of ultra-high performance fibre reinforced concrete (UHPFRC). Cem. Concr. Res. 2014, 56, 29-39. [CrossRef]

12. Bonneau, O.; Lachemi, M.; Dallaire, E.; Dugat, J.; Aitcin, P.-C. Mechanical properties and durability of two industrial reactive powder concretes. ACI Mater. J. 1997, 94, 286-290.

13. Yazici, H.; Yardimci, M.Y.; Aydin, S.; Karabulut, A.Ş. Mechanical properties of reactive powder concrete containing mineral admixtures under different curing regimes. Constr. Build. Mater. 2009, 23, 1223-1231. [CrossRef]

14. Yazici, H.; Deniz, E.; Baradan, B. The effect of autoclave pressure, temperature and duration time on mechanical properties of reactive powder concrete. Constr. Build. Mater. 2013, 42, 53-63. [CrossRef]

15. Ipek, M.; Yilmaz, K.; SSümer, M.; Saribiyik, M. Effect of pre-setting pressure applied to mechanical behaviours of reactive powder concrete during setting phase. Constr. Build. Mater. 2011, 25, 61-68. [CrossRef]

16. Halit, $Y$. The effect of curing conditions on compressive strength of ultra high strength concrete with high volume mineral admixtures. Build. Environ. 2007, 42, 2083-2089.

17. Cwirzen, A. The effect of the heat-treatment regime on the properties of reactive powder concrete. Adv. Cem. Res. 2007, 19, 25-33. [CrossRef]

18. Hiremath, P.N.; Yaragal, S.C. Influence of mixing method, speed and duration on the fresh and hardened properties of Reactive Powder Concrete. Constr. Build. Mater. 2017, 141, 271-288. [CrossRef]

19. Abbas, S.; Soliman, A.M.; Nehdi, M.L. Exploring mechanical and durability properties of ultra-high performance concrete incorporating various steel fiber lengths and dosages. Constr. Build. Mater. 2015, 75, 429-441. [CrossRef]

20. Zheng, W.; Luo, B.; Wang, Y. Compressive and tensile properties of reactive powder concrete with steel fibres at elevated temperatures. Constr. Build. Mater. 2013, 41, 844-851. [CrossRef]

21. Liu, S.H.; Yan, P.Y.; Feng, J.W. Research and application of RPC in the bridge engineering. Highway 2009, 58, 149-154.

22. Song, J.; Liu, S. Properties of reactive powder concrete and its application in highway bridge. Adv. Mater. Sci. Eng. 2016, 2016, 5460241. [CrossRef]

23. Tulebekova, S.; Saliyev, D.; Zhang, D.; Kim, J.R.; Karabay, A.; Turlybek, A.; Kazybayeva, L. Preliminary Analytical Study on the Feasibility of Using Reinforced Concrete Pile Foundations for Renewable Energy Storage by Compressed Air Energy Storage Technology. In IOP Conference Series: Materials Science and Engineering; IOP Publishing Ltd.: London, UK, 2017; Volume 271, pp. 12-23. [CrossRef] 
24. Bektimirova, U.; Tleuken, A.; Satekenova, E.; Shon, C.S.; Zhang, D.; Kim, J.R. Preliminary Experimental Investigation on the Strength and Air Permeability of Reactive Powder Concrete. Mater. Sci. Forum 2018, 917, 321-328. [CrossRef]

25. Sabirova, A.; Zhang, D.; Kim, J.R.; Nguyen, M.; Shon, C.S. Development of a Reinforced Concrete Foundation System for Renewable Energy Storage. In Challenges and Innovations in Geotechnics_Proceedings of the 8th Asian Young Geotechnical Engineers Conference, Astana, Kazakhstan, 5-7 August 2016; 8AYGEC 2016; CRC Press: Boca Raton, FL, USA, 2016; pp. 119-122.

26. Zhang, D.; Kim, J.; Tulebekova, S.; Saliyev, D.; Lee, D.H. Structural Responses of Reinforced Concrete Pile Foundations Subjected to Pressures from Compressed Air for Renewable Energy Storage. Int. J. Concr. Struct. Mater. 2018, 12, 1-16. [CrossRef]

27. American Society for Testing and Materials. Standard Test Method for Compressive Strength of Hydraulic Cement Mortars; ASTM C109; ASTM International: West Conshohocken, PA, USA, 2016.

28. American Society for Testing and Materials. Standard Test Method for Flow of Hydraulic Cement Mortar; ASTM C1437; ASTM International: West Conshohocken, PA, USA, 2007.

29. American Society for Testing and Materials. Standard Test Method for Time of Setting of Concrete Mixtures by Penetration Resistance; ASTM C403; ASTM International: West Conshohocken, PA, USA, 2001.

30. American Society for Testing and Materials. Standard Test Method for Flexural Strength of Concrete (Using Simple Beam with Center-Point Loading); ASTM C293; ASTM International: West Conshohocken, PA, USA, 2001.

31. American Society for Testing and Materials. Standard Test Method for Length Change of Hardened Hydraulic-Cement Mortar and Concrete; ASTM C157; ASTM International: West Conshohocken, PA, USA, 2015.

32. American Society for Testing and Materials. Standard Practice for Use of Apparatus for the Determination of Length Change of Hardened Cement Paste, Mortar, and Concrete; ASTM C490; ASTM International: West Conshohocken, PA, USA, 2015.

33. Lohtia, R.P.; Joshi, R.C. Mineral admixtures. In Concrete Admixture Handbook; Ramachandran, V.S., Ed.; Noyes Publications: Park Ridge, NJ, USA, 1996; 1153p.

34. Elaty, M.A.A.; Ghazy, M.F. Performance of Portland cement mixes containing silica fume and mixed with lime-water. HBRC J. 2014, 10, 247-257. [CrossRef]

35. Rao, G.A. Investigations on the performance of silica fume-incorporated cement pastes and mortars. Cem. Concr. Res. 2003, 33, 1765-1770. [CrossRef]

36. Dave, N.; Misra, A.K.; Srivastava, A.; Kaushik, S.K. Setting time and standard consistency of quaternary binders: The influence of cementitious material addition and mixing. Int. J. Sustain. Built Environ. 2017, 6, 30-36. [CrossRef]

37. Soroka, I. Portland Cement Paste and Concrete; The Macmillan Press Ltd.: London, UK, 1979; pp. 87-91.

38. Verbeck, G.J.; Helmuth, R.H. Structure and physical properties of cement paste. In Proceedings of the Fifth International Symposium on the Chemistry of Cement, Tokyo, Japan, 7-11 October 1968; Part III, pp. 1-32.

39. Kayali, O.; Haque, M.N.; Zhu, B. Drying shrinkage of fibre-reinforced lightweight aggregate concrete containing fly ash. Cem. Concr. Res. 1999, 29, 1835-1840. [CrossRef]

40. Kim, J.J.; Taha, M.R. Experimental and Numerical Evaluation of Direct Tension Test for Cylindrical Concrete Specimens. Adv. Civ. Eng. 2014, 2014, 156926. [CrossRef]

(C) 2018 by the authors. Licensee MDPI, Basel, Switzerland. This article is an open access article distributed under the terms and conditions of the Creative Commons Attribution (CC BY) license (http://creativecommons.org/licenses/by/4.0/). 